\title{
INFLATION RISKS
}

AND INFLATION

RISK PREMIA

by Juan Angel García

and Thomas Werner 
EUROSYSTEM

\title{
WORKING PAPER SERIES
}

NO II62 I MARCH 2010

\author{
INFLATION RISKS AND \\ INFLATION RISK PREMIA'
}

by Juan Angel García and Thomas Werner

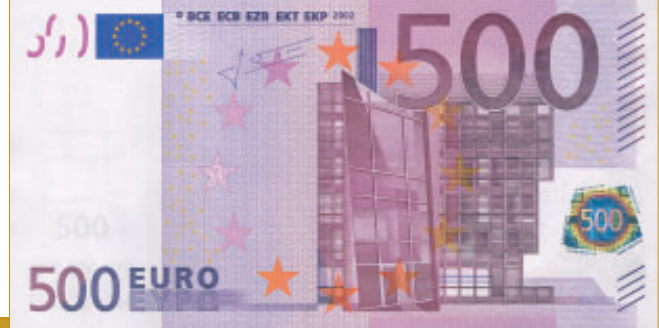

In 2010 all ECB

publication

feature a motif

taken from the

$€ 500$ banknote.

NOTE: This Working Paper should not be reported as representing the views of the European Central Bank (ECB).

The views expressed are those of the authors and do not necessarily reflect those of the ECB.

This paper can be downloaded without charge from http://www.ecb.europa.eu or from the Social Science Research Network electronic library at http://ssrn.com/abstract_id $=1569383$.

I We thank Geert Bekaert, Hans Dewachter, Refet Gürkaynak, Philippe Mueller and participants in the ECB workshop "Measuring and interpreting the inflation risk premia for monetary policy", the Bank of Spain and the Central Bank of Cyprus for useful suggestions and comments. We are particularly indebted to Andrés Manzanares. Any remaining errors are our responsibility. 2 Both authors: European Central Bank, Capital Markets and Financial Structure Division, Kaiserstrasse 29, 603II Frankfurt am Main, Germany; e-mail: juan_angel.garcia@ecb.europa.eu; thomas.werner@ecb.europa.eu 
CC European Central Bank, 2010

\section{Address}

Kaiserstrasse 29

60311 Frankfurt am Main, Germany

Postal address

Postfach 160319

60066 Frankfurt am Main, Germany

Telephone

+496913440

Internet

http://www.ecb.europa.eu

Fax

+496913446000

All rights reserved.

Any reproduction, publication and reprint in the form of a different publication, whether printed or produced electronically, in whole or in part, is permitted only with the explicit written authorisation of the ECB or the authors.

Information on all of the papers published in the ECB Working Paper Series can be found on the ECB's website, http://www. ecb.europa.eu/pub/scientific/wps/date/ html/index.en.html

ISSN 1725-2806 (online) 


\section{CONTENTS}

Abstract

Non-technical summary

1 Introduction

2 Estimating the (euro area) inflation risk premium

2.1 Model setup

2.2 Data and estimation method

2.3 The role of (survey) inflation expectations

3 Inflation compensation and inflation risk premia

4 Inflation risks

4.1 Measuring inflation risks

4.2 Perceived inflation risks in the euro area

5 Interpreting developments in inflation risk premia

6 Concluding remarks

7 Appendices

References

Tables and figures 


\begin{abstract}
This paper investigates the link between the perceived inflation risks in macroeconomic forecasts and the inflation risk premia embodied in financial instruments. We first provide some stylized facts about the term structure of inflation compensation, inflation expectations and inflation risk premia in the euro area bond market. Latent factor models like ours fit data well, but are often critisized for lacking economic interpretation. Using survey inflation risks, we show that perceived asymmetries in inflation risks help interpret the dynamics of long-term inflation risk premia, even after controlling for a large number of macro and financial factors.
\end{abstract}

Keywords: Affine term structure models, state-space modelling, inflation compensation, inflation risk premia, inflation risks

JEL Classification: G12, E31, E43 


\section{Non-technical summary}

The yield spread between nominal and inflation-linked bonds, commonly referred to as the break-even inflation rate (BEIR), has become one of the most important indicators of inflation expectations. Since most major economies have issued inflation-linked debt in recent years, references to BEIRs in central bank publications and speeches, research on the anchoring of inflation expectations, and regular market commentary are nowadays increasingly common. BEIRs reflect the overall inflation compensation requested to hold nominal bonds, comprising both the expected level of inflation and a premium to compensate for inflation risks. From a policy and a research perspective, understanding the dynamics of the inflation risk premium is crucial, but its estimation is challenging and its interpretation is often far from straightforward.

At the same time, the discussion of the risks surrounding the inflation outlook is an increasingly important element in macroeconomic forecasting and monetary policy. Attention in macro forecasts used to be restricted to single point predictions. Professional forecasters however rarely think in terms of point predictions only, and nowadays most central bank statements, specialised media and market commentary usually elaborate at some length on the "risks" in their inflation forecasts

This paper seeks for the link between the inflation risks in macroeconomic forecasts and the inflation risk premia embodied in the term structure of interest rates. To that end, we first report some new quantitative evidence on both the term structure of inflation risk premia and the risk surrounding the inflation outlook in the euro area. We then investigate which of our measures of risks are priced in in bond markets.

To present stylised facts about the term structure of BEIRs, inflation expectations and inflation risk premia in the euro area, we employ a no-arbitrage term structure model with nominal bonds and inflation. No-arbitrage conditions alone however provide weak identifying restrictions for real yields and the inflation risk premia. To improve the estimation and decomposition of BEIRs, our model incorporates two key pieces of additional information. First, we use inflation-linked bond yields to identify real yields and second, we employ survey inflation expectations to help estimate the level of expected inflation and better identify the inflation risk premia. 
The novelty of our analysis lies on the extensive use of survey data on inflation expectations. We first show that introducing survey inflation expectations in a term structure model helps obtain realistic estimates of the inflation risk premia. Our analysis also shows that survey inflation expectations do provide additional information to interpret developments in the term structure. Specifically, using survey probability forecasts, we present some new quantitative evidence on perceived inflation risks over different horizons, and show that the dynamics of inflation risk premia can be explained using survey-based measures of perceived inflation risks.

Our main findings are as follows. As regards euro area inflation compensation, the BEIR term structure is predominantly upward sloping but quite flat. The term structure of inflation risk premia is also upward sloping but also quite compressed (from 7 basis points one-year ahead to 25 basis points at longer horizons). Market's inflation expectations are, in turn, fairly stable around $2 \%$ at medium-to-long horizons. As regards perceived inflation risks surrounding euro area inflation expectations, inflation risks do not strongly correlate with (mean) inflation expectations or actual inflation rates, neither at short nor at long horizons. In contrast, the "balance of risks" (asymmetry) surrounding inflation expectations displays some interesting variations over time and across horizons, including changing signs.

On the relationship between perceived inflation risks and the inflation risk premia, our main finding is that those measures of inflation risks help interpret developments in the inflation risk premia embodied in bond yields. Specifically, at long horizons the dynamics of inflation risk premia mimics those of the perceived asymmetries of inflation risks, the so-called "balance of risks", and not the inflation uncertainty, We also show that the explanatory power of the asymmetries in inflation risks is robust to considering a large number of macroeconomic and financial factors capturing not only inflationary pressures (core and headline inflation) but also economic activity (output gap, unemployment rate) and confidence indicators (consumer and industrial confidence) as well as standard risk indicators in financial markets (yield spread, bond and stock market volatility). 


\section{Introduction}

The yield spread between nominal and inflation-linked bonds, commonly referred to as the break-even inflation rate (BEIR), has become a key indicator of inflation expectations. Since most major economies have issued inflation-linked debt in recent years, references to BEIRs in central bank publications and speeches (e.g. Bernanke, 2007, Trichet, 2005), research on the anchoring of inflation expectations (e.g. Gürkaynak, Levin and Swanson, 2009), and regular market commentary are nowadays common. BEIRs reflect the overall inflation compensation requested to hold nominal bonds, comprising both the expected level of inflation and a premium to compensate for inflation risks. From a policy and a research perspective, understanding the dynamics of the inflation risk premium is crucial, but its estimation is challenging and its interpretation is often far from straightforward

At the same time, the discussion of the risks surrounding the inflation outlook is an increasingly important element in macroeconomic forecasting. Attention in macro forecasts used to be restricted to single point predictions. Professional forecasters however rarely think in terms of point predictions only, and nowadays most central bank statements, specialized media and market commentary usually elaborate at some length on the "risks" in their inflation forecasts. Indeed, providing quantitative evidence on the uncertainty and risk asymmetries surrounding inflation forecasts is becoming a standard practice (see Blix and Sellin, 1998, and Britton et al.,1998).

We seek for the link between the inflation risks in macroeconomic forecasts and the inflation risk premia embodied in the term structure of interest rates. To that end, this paper first presents some new quantitative evidence on both the term structure of inflation risk premia and the risks surrounding the inflation outlook in the euro area. We then investigate which measures of inflation risks are priced in at different horizons and show that perceived asymmetries in inflation risks help interpret the dynamics of long-term inflation risk premia.

To estimate the term structure of euro area BEIRs and inflation risk premia, we 
built a no-arbitrage term structure model along the lines of Ang, Bekaert and Wei (2008). The model employs actual inflation and two latent factors to fit euro area bond market data. To improve the estimation and decomposition of BEIRs, our model incorporates two key pieces of additional information: inflation-linked bond yields and survey inflation expectations. The former provide information about real yields (e.g. D'Amico, Kim and Wei, 2007, and Hördalh and Tristani, 2007), and the latter allow to pin down the level of expected inflation and thereby better identify the inflation risk premia over the period of single monetary policy in the euro area.

To obtain quantitative measures of inflation risks we use data from the Survey of Professional Forecasters of the European Central Bank (ECB's SPF). As for the more widely-used US SPF currently run by the Federal Reserve Bank of Philadelphia, ECB's SPF panelists assign probabilities to future inflation falling into pre-specified ranges, i.e. a density forecast in the form of a histogram. Moreover, such information is collected for three different horizons (one, two and five years ahead), thereby providing a term structure of inflation risks. Following Garcia and Manzanares (2007), we fit a continuous density to the SPF histograms and, at each of those horizons, obtain the mean forecasts, and two metrics of the risks, namely the degree of uncertainty and the asymmetry of risks, surrounding them. We use that term structure of inflation expectations and perceived inflation risks in the estimation and interpretation of our model.

This paper is therefore closely related to some recent developments in the literature on term structure modelling. Factor models of the term structure of interest rates fit data well, but are often criticized because, being based on unobservable factors, their results lack direct economic interpretation. Some recent term structure models therefore combine both macroeconomic variables and latent factors to help interpret movements in the yield curve in general and the inflation risk premia in particular (e.g. Ang and Piazzesi, 2003). Most recent term structure models also incorporate survey data on inflation expectations. Chernov and Mueller (2008) show that modelling together yields 
and survey inflation forecasts is important to produce reasonable inflation expectations in term structure models. This paper contributes to that growing literature by extending the use of inflation survey information to the estimation and interpretation of the term structure of inflation risk premia. To the extent that a limited number of observable economic factors may not adequately represent the information sets of investors (see Bekaert, Cho and Moreno, 2009, Mönch, 2008), survey measures of inflation risks can therefore provide an alternative to interpret the dynamics of inflation risk premia by comprising information from a potentially large set of macro factors without facing the risk of misspecifying the macroeconomic model.

Our main contributions are as follows. We first document some stylized facts about the inflation compensation in euro area bond yields and perceived inflation risks at short and long horizons. As regards euro area inflation compensation, the BEIR term structure is predominantly upward sloping but quite flat: BEIRs averaged 2.0\% two-year ahead and only $2.15 \%$ five years ahead. The term structure of inflation risk premia is also upward sloping but quite compressed (from 7 basis points one-year ahead to 25 basis points at longer horizons). While short-term inflation expectations appear influenced by actual inflation dynamics, at medium-to-long horizons market's inflation expectations are quite stable and fluctuate around $2 \%$. The variation of inflation compensation decreases with maturity, and reflects different factors across maturities: inflation expectations explain about $2 / 3$ of the variation of short-term BEIRs, while the variation of long-term BEIRs is mainly driven by the inflation risk premia.

As regards perceived risks surrounding euro area inflation expectations, we also document some stylised facts about the dynamics of the term structure of inflation risks over the first years of the ECB. We show that inflation risks provide information beyond that contained in point predictions, rich information that is very useful for both policy and research alike. Indeed inflation risks show a limited correlation with (mean) inflation expectations, or actual inflation rates, neither at short nor at long horizons. Inflation uncertainty displays a stronger link to core than to headline 
inflation, which partly explains its little variation over time. In contrast, the balance of risks surrounding inflation expectations does exhibit significant shifts over time and across horizons, including changing signs. In particularly, euro area long-term inflation expectations were positively skewed in the early years of the single monetary policy, turned negatively skewed between 2003 and 2005, but in the last few years upside risks predominated again.

Our main finding is that those measures of inflation risks help interpret developments in the inflation risk premia embodied in bond yields. Specifically, at long horizons the dynamics of inflation risk premia mimics those of the perceived asymmetries of inflation risks. Indeed, it is the perceived asymmetry in inflation risks, the so-called "balance of risks", and not the inflation uncertainty, which seems to be crucial to understand the dynamics of inflation risk premia. Our results therefore suggest that markets price in the asymmetries in inflation risks rather than their standard deviation over long horizons. We also show that the explanatory power of the asymmetries in inflation risks is robust to considering a large number of macroeconomic and financial factors capturing not only inflationary pressures (core and headline inflation) but also economic activity (output gap, unemployment rate) and confidence indicators (consumer and industrial confidence) as well as standard risk indicators in financial markets (yield spread, bond and stock market volatility).

The paper is organized as follows. Section 2 introduces the term structure model we use to estimate the inflation risk premia (full details are presented in Appendix A), and Section 3 reports some stylized facts about inflation compensation and inflation risk premia in the euro area. Section 4 provides some stylized facts on perceived inflation risks (Appendix B describes our estimation approach in detail). In Section 5 we investigate the link between inflation risks and inflation risk premia and show that perceived inflation risks help interpret the dynamics of inflation risk premia. Section 6 finally concludes. 


\section{Estimating the (euro area) inflation risk premium}

The spread between the yield of nominal bond $\left(y_{t}^{n}\right)$ and the yield of a real bond $\left(y_{t}^{r}\right)$ of the maturity $n$ reflects the inflation compensation requested by investors to hold nominal bonds, and it is commonly referred to as break-even inflation rate (BEIR henceforth). The required compensation for inflation, or BEIR, however comprises two very distinct components, namely the (average) level of inflation over the life of the bond $\left(E_{t}\left(\pi_{t, t+n}\right)\right)$ and an additional risk premium $\left(\phi_{t}^{n}\right)$ requested by bond holders as compensation for the risk of inflation turning out being different from that expectation. Formally,

$$
y_{t}^{n}-y_{t}^{r}=B E I R=E_{t}\left(\pi_{t, t+n}\right)+\phi_{t}^{n} .
$$

In this section we seek to establish some stylized facts about the inflation risk premium embodied in euro area government bonds. A serious challenge to interpret developments in nominal yields and to estimate BEIRs, is that not only the inflation risk premium but, to a large extent, also expected inflation and the real yield are unobservable, and therefore need to be identified from the observed bond yields.

\subsection{Model setup}

To estimate the term structure of inflation risk premia, we employ a discrete-time affine term structure framework that links bond yields to the dynamics of short-term yields and inflation under no-arbitrage restrictions. The basic structure of our framework is similar to Ang, Bekaert and Wei (2008, ABW henceforth), so we here only provide an overview of the model and present full details in Appendix A.

No-arbitrage conditions alone however provides weak identifying restrictions for real yields and the inflation risk premia, so we incorporate additional information to improve the decomposition of BEIRs. Specifically, in line with recent literature, to better estimate real yields we incorporate inflation-linked bond yields in the estimation (e.g. D'Amico, Kim and Wei, 2007, DKW henceforth, Hördalh and Tristani, 2007). 
In addition, to help estimate the inflation risk premia, we incorporate survey data of inflation expectations at both short and longer-term horizons. Using survey data on inflation expectations helps estimate the inflation risk premia because an accurate estimation of the term structure of expected inflation is crucial for the decomposition of nominal yields, and, in particular, inflation compensation (see Kim, 2007, Chernov and Mueller, 2008 for detailed discussions).

Our model has three state variables: two latent factors $l_{t}^{1}, l_{t}^{2}$, and actual inflation $\pi_{t}$ as observable factor. As standard in the related literature, the dynamics of the state vector $X_{t}=\left(l_{t}^{1} l_{t}^{2} \pi_{t}\right)^{\prime}$ follows a $\operatorname{VAR}(1)$ process $X_{t+1}=\mu+\Phi X_{t}+\Sigma \epsilon_{t+1}$. The structure of $\mu, \Phi$ and $\Sigma$ is as follows

$$
\mu=\left[\begin{array}{l}
0 \\
0 \\
\mu_{\pi}
\end{array}\right], \quad \Phi=\left[\begin{array}{ccc}
\Phi_{11} & 0 & 0 \\
\Phi_{21} & \Phi_{22} & 0 \\
\Phi_{31} & \Phi_{32} & \Phi_{33}
\end{array}\right], \quad \Sigma=\left[\begin{array}{ccc}
1 & 0 & 0 \\
0 & 1 & 0 \\
0 & 0 & \sigma_{\pi}
\end{array}\right]
$$

As in $\mathrm{ABW}$, the ordering of the state variables leads to a rich inflation dynamics, as inflation depends on its own lagged values and the two latent factors. The real short rate $\hat{r}_{t}$ is an affine function of the state vector $\hat{r}_{t}=\delta_{0}+\delta_{1}^{\prime} X_{t}$, and, in order to make the real rate dependent on the latent factors but not on inflation, ${ }^{1}$ we restrict the $\delta_{1}$ vector to $\left(\begin{array}{lll}\delta_{1,1} & \delta_{1,2} & 0\end{array}\right)$. To model the term structure of real yields, we specify the real pricing kernel as an exponential function of the market price of risk $\lambda_{t}$ :

$$
\hat{M}_{t}=\exp \left(-\hat{r}_{t}-\frac{1}{2} \lambda_{t}^{\prime} \lambda_{t}-\lambda_{t}^{\prime} \epsilon_{t+1}\right)
$$

The market price of risk, in turn, is a linear affine function of the state variables $\lambda_{t}=\lambda_{0}+\lambda_{1} X_{t}$, which we restrict to make the real part of the model to be fully

\footnotetext{
${ }^{1}$ From a theoretical point of view, by imposing this restriction we exclude the Mundell-Tobin effect that captures the influence of inflation on the real interest rate. In practice, relaxing such a restriction had minor effects in the estimation, which can be interpreted as a validation of our assumption.
} 
determined by the latent factors ${ }^{2}$ :

$$
\lambda_{0}=\left[\begin{array}{c}
\lambda_{0,1} \\
\lambda_{0,2} \\
0
\end{array}\right], \quad \lambda_{1}=\left[\begin{array}{ccc}
\lambda_{1,11} & \lambda_{1,12} & 0 \\
\lambda_{1,21} & \lambda_{1,22} & 0 \\
0 & 0 & 0
\end{array}\right]
$$

The expected evolution of the real pricing kernel determines real bond prices,

$\hat{P}_{t}^{n}=E_{t}\left(\hat{M}_{t+1} \hat{M}_{t+2} \ldots \hat{M}_{t+n}\right)$, and the (log) prices and yields of real bonds are affine functions of the states:

$$
\hat{P}_{t}^{n}=\exp \left(\hat{A}_{n}+\hat{B}_{n}^{\prime} X_{t}\right), \quad \text { and } \quad y_{t}^{r}=-\frac{\log \left(\hat{P}_{t}^{n}\right)}{n}=-\frac{1}{n}\left(\hat{A}_{n}+\hat{B}_{n}^{\prime} X_{t}\right)
$$

Using the fact that inflation links the nominal and the real pricing kernels as follows

$$
M_{t+1}=\frac{\hat{M}_{t+1} C P I_{t}}{C P I_{t+1}}=\frac{\hat{M}_{t+1}}{\Pi_{t+1}}
$$

the expressions for nominal bond prices and yields are similar to those for their real counterparts. ${ }^{3}$

\subsection{Data and estimation method}

\subsubsection{Data}

The estimation of the model is based on 3-month, and 1,2,3 and 5-year nominal zero-coupon yields from Bloomberg over the sample January 1995 to December $2006 .{ }^{4}$ The 2, 3, and 5-year real zero-coupon yields are derived from inflation-linked bond yields following Ejsing et al. (2007) for the period February 2004 to December 2006. Inflation is calculated as the year-on-year rate of change in the euro area HICP figures as reported by Eurostat. The survey-based measures of inflation expectations are from the

\footnotetext{
${ }^{2}$ The restrictions on $\lambda_{0}$ and $\lambda_{1}$ facilitate the estimation but do not affect our results.

${ }^{3}$ Full model details can be found in Appendix A.

${ }^{4}$ Nominal yields before 1999 are yields derived from German government bonds.
} 
ECB's SPF, and we will describe them in detail below. In line with the ECB's inflation objective, survey inflation expectations refer to the year-on-year rate of change of the euro area HICP.

For our comparison to the survey inflation risks we will restrict attention to the period 1999M1-2006M12. Our choice is motivated by two main considerations. First, the ECB's Survey of Professional Forecasters (to be described in detail in the next section), which is our source of evidence on perceived inflation risks, was launched in 1999, as the ECB took responsibility for the single monetary policy in the euro area. Second, 1999-2006 is a period long enough to investigate the link between inflation risks and inflation risk premia while at the same time helps avoid data distortions stemming from the financial turbulences since the summer of 2007. In particular, the time-varying nature of the liquidity premium embodied in nominal and real bond yields since mid2007 is quite difficult to correct for (see DKW, 2007) and can potentially cloud the relationship we aim at unveiling here.

Some basic statistics of the yield curve data over our sample are presented in Table 1. The euro area nominal, real and BEIR curves were relatively flat but predominantly upward sloping. Those curves displayed significantly higher volatility at the short-end than over longer horizons, which in the case of the nominal and the BEIR curves probably reflects the strong anchoring of inflation expectations in the euro area. The levels of the yields tended to be positively skewed, but nonetheless exhibited negative excess kurtosis across all horizons, further corroborating relatively low volatility. Despite those mild non-Gaussian features, the Gaussian assumption does not seem to be unreasonable as a first approximation to gauge reliable estimates of the euro area term structure of inflation risk premia and its dynamics and to compare them to the dynamics of perceived inflation risks. 


\subsubsection{State and observation equations}

The measurement and transition equations on the state-space representation of the model are as follows:

$$
\begin{array}{lr}
w_{t}=d+Z X_{t}+\eta_{t} & \text { (measurement equation) } \\
X_{t}=\mu+\Phi X_{t-1}+\Sigma \epsilon_{t} & \text { (state equation). }
\end{array}
$$

The vector of observed data $w_{t}$ contains real and nominal bond yields, inflation and the survey inflation expectations. The vector $d$ and the matrix $Z$ reflect the bond price equations that link the state variables (latent factors) and the observed data (see Appendix A for details).

A crucial aspect of our modelling choice is the possibility to identify model-based inflation expectations using the information from survey inflation expectations, but allowing for discrepancies between the two through measurement errors. As inflation is included as observable variable in the state vector, model-based inflation expectations are, for all forecast horizons, a function of the states in time $t$. For example, the model-based inflation expectation for inflation two years ahead (in 24 months) can be computed as: ${ }^{5}$

$$
E_{t}^{\text {model }}\left[\pi_{t+24}\right]=e_{3}\left(I-\Phi^{24}\right)(I-\Phi)^{-1} \mu+e_{3} \Phi^{24} X_{t}
$$

Matching model-based inflation expectations and survey based inflation expectations by allowing for measurement errors helps identifying inflation expectations, and thereby inflation risk premia, without forcing the model to fit the survey expectations fully.

\footnotetext{
${ }^{5}$ Thereby $e_{3}$ is a vector of zeros apart from the third element that contains a one. This vector selects inflation from the state vector.
} 


\subsubsection{Kalman filtering and optimization}

For practical implementation, we formulate the model in state-space form and use Kalman filtering techniques in the estimation. In our context, this approach offers two main advantages. First, we incorporate additional data in the estimation as they become available. We incorporate yields from inflation-linked bonds only from 2004 onwards, because before that date yields on euro area inflation-linked bonds incorporate a significant liquidity premium that is difficult to correct for (see DKW, 2007, for a detailed discussion). ${ }^{6}$ Survey inflation expectations are another key piece of information in our model that is only available since 1999, and at a quarterly frequency. The statespace formulation therefore fits well with those features of our dataset. Second, we fit real and nominal bonds at all maturities allowing for measurement error. Indeed, in line with the common belief that the inflation-linked bonds whose yields help pin down real yields may still be somewhat less liquid than nominal bonds, measurement errors for inflation-linked bond yields are higher than those for their nominal counterparts.

Regarding the optimization method for finding the likelihood estimate we use a combination of the simplex method and a subgradient method. ${ }^{7}$ This approach allows for dealing with flat areas in the likelihood function that makes optimization quite challenging for standard gradient methods. Confidence bounds for the parameter estimates are computed using MCMC sampling with flat priors. ${ }^{8}$ Table 2 reports the estimation results for the main parameters of the model and their $95 \%$ confidence bounds.

\subsection{The role of (survey) inflation expectations}

Our model estimates the spread between nominal and real yields of equal maturities (BEIRs) using data from inflation-linked and nominal bonds, and decomposes those BEIRs into inflation expectations and inflation risk premia with the help of survey

\footnotetext{
${ }^{6}$ García and Van Rixtel (2007) reviews the development of the euro area index-linked bond market.

${ }^{7}$ See the following URL for details: http://www.kfunigraz.ac.at/imawww/kuntsevich/solvopt/.

${ }^{8}$ The justification for applying MCMC allows to construct confidence bounds that are much more robust compared to standard methods relying on second-order numerical approximation of the likelihood function (see Chernozhukov and Hong, 2003).
} 
inflation expectations at different horizons.

Recent findings have questioned the quality of the inflation expectations generated endogenously by term structure models like ours. Ang et al. (2007) find that survey inflation expectations outperform not only no-arbitrage term structure models but also a wide range of univariate and multivariate models. Kim (2007) also shows that surveys outperform models in forecasting inflation especially at longer horizons because surveys better capture both the trend component of inflation and the variations in the perceived long-run inflation target (the shifting end-point of inflation in Kozicki and Tinsley, 2001, Dewachter and Lyrio, 2008). This is particularly important to model inflation risk premia at long-run horizons, as, in the current context of strongly anchored inflation expectations, few would question that the link between the short-run inflation dynamics and long-run inflation expectations is weak.

Since pinning down inflation expectations is crucial for estimating the inflation risk premia, the use of survey inflation expectations in the estimation of term structure models has become a standard practice (e.g. DKW, 2007, Hördahl and Tristani,2008, Joyce et al., 2009). Following those recent contributions, we use information from the Survey of Professional Forecasters of the European Central Bank (ECB's SPF), a quarterly survey that collects euro area inflation expectations one, two and five years ahead. ${ }^{9}$ In practise, such data allows for pinning down a full term structure of inflation expectations, capturing the distinct factors influencing inflation expectations at different horizons without modelling them and therefore avoiding the risk of misspecification.

Imposing a perfect fitting of survey expectations could however be too demanding for the model and even potentially problematic, for market's consensus expectations could differ from those reflected in inflation surveys. Chernov and Mueller (2008) elaborate at length on this point. Specifically, (standard) term structure models can determine inflation expectations at any horizon under the historical measure. Survey results in contrast comprise information from a relatively large number of subjective percep-

\footnotetext{
${ }^{9}$ Garcia (2003) describes the history and information collected by the ECB's SPF.
} 
tions and may therefore be different from both that risk-neutral probability measure and the historical probability measure defined by the joint dynamics of all information in the term structure model. To account for that potential discrepancy, we include survey inflation expectations into the measurement equation of the state-space model representation, but allow for measurement errors in their fitting. ${ }^{10}$

Using estimations of our model including and not including information from survey data, we now present some quantitative evidence in support of the use of inflation survey data. We focus on the dimensions of the model-based inflation expectations that are crucial for the estimation of inflation risk premia, namely the volatility of inflation expectations and the fit of the observed bond yields. The results reported here, while offering some additional perspective on the estimation of inflation expectations embodied in bond yields through term structure models, overall corroborate the findings of Kim (2007) and Chernov and Mueller (2008) for euro area data.

First, including survey data to the model improves the fit of the observed level of inflation expectations at all horizons (see Table 3). Second, including inflation survey data also contributes to bring the dynamics of the inflation expectations more in line with the evidence suggested by survey data. Without including survey data, the volatility of model inflation expectations is significantly higher than that from the observed inflation expectations at all horizons (see Table 3). These two results seems to stem from the fact that model-based inflation expectations are too influenced by actual inflation developments, whose high volatility translates into highly volatile inflation expectations at all horizons. Incorporating survey measures of inflation expectations in the estimation does reduce that volatility. In particular, as inflation expectations at longer horizons are better anchored nowadays (Table 4 suggests they are about four times less volatile than shorter-term inflation expectations and even much less than realized inflation), reducing the volatility of inflation expectations by using survey data in the model estimation is therefore welcome when estimating inflation risk premia at

\footnotetext{
${ }^{10}$ See Appendix, section A.2 for details.
} 
long horizons.

Importantly, better estimation of the term structure of inflation expectations using survey expectations does not come at the cost of fitting financial data. If fitting survey expectations would distort the model performance in other dimensions, e.g. fitting the real and nominal yield curves, then, even with the right measure of inflation expectations, the estimation of the inflation risk premium could deteriorate. Table 5 however shows that the fitting of nominal yields in the model including survey data is as good as, and often somewhat better, than that of the model estimated without including survey information.

\section{Inflation compensation and inflation risk premia}

This section describes the dynamics of inflation compensation in the euro area over the sample 1999M1-2006M12, and, in particular, the role of inflation expectations and inflation risk premia in driving inflation compensation at different horizons. We focus on one-year forward rates of inflation compensation ending in one, two and five years, because inflation surveys by design collect year-on-year rates of inflation at those horizons, and they are a key piece of information in our model. Moreover, later in this paper we also use survey measures of inflation risks at those horizons to interpret the dynamics of the term structure of euro area inflation risk premia. ${ }^{11}$

Table 6 reports the main characteristics of the inflation compensation (BEIRs), expected inflation and the inflation risk premium (see also Figures 1 to 3). First, as regards euro area BEIRs themselves, the term structure of euro area inflation compensation has been predominantly upward sloping but relatively flat: the spread between nominal and real yields at the two year horizon has been, on average, of around 200 basis points, and, despite rising with maturity, at the five year horizon it has averaged 215 basis points, just 15 basis points more. The difference between the levels of the one

\footnotetext{
${ }^{11}$ Note that Equation (1) also establishes the link among forward inflation compensation, inflation expectations and forward inflation risk premia.
} 
year forward BEIRs ending in two and five years peaked at around 30 basis points in early 2000 and early 2002. Later in the sample, over the so-called "conundrum" period between mid-2004 and end-2006, the term structure of inflation compensation flattened considerably, and that difference remained within 10 basis points.

The term structure of inflation risk premia also exhibits a predominantly upward slope but, as for headline inflation compensation, the spread across maturities is quite compressed: on average the one year ahead inflation risk premium was about 7 basis points, two year ahead 10 basis points and four year ahead 25 basis points. Moreover, the long-term premia oscillated within a relatively narrow range of 0-50 basis points. The upward sloping term structure of inflation risk premia matches the upward slope of overall inflation compensation. Our estimates of inflation expectations embodied in bond yields, in line with the evidence from survey data, suggest a strong anchoring of inflation expectations at medium-to-long maturities.

To better interpret the dynamics of euro area BEIRs, Table 6 also reports the relative contributions of inflation expectations and the inflation risk premia to the volatility of overall inflation compensation. Short horizon BEIRs are more volatile than longer ones, and about $2 / 3$ of that volatility reflects movements in short-term inflation expectations, with inflation risk premia playing a limited role. Although one year forward BEIRs in two and four years exhibit a relatively similar volatility, with standard deviations of about 0.15 in both cases, there are substantial differences in terms of their variance decomposition. While the contributions of inflation expectations and the inflation risk premium to the volatility of short-to-medium-horizon BEIRs appears quite balanced, the volatility of inflation compensation at longer horizon is almost fully driven by the inflation risk premia. The role of fluctuations in long-term inflation expectations is rather limited, which is consistent with a strong anchoring of euro area inflation expectations. This result highlights the importance of accounting for this feature of inflation expectations when modelling long-term inflation risk premia. In this regard, our model-based inflation expectations, which combine information from 
both survey and financial data, suggest that long-term inflation expectations among market participants may be even more firmly anchored that survey data suggest: with a standard deviation of about 0.03, model-based inflation expectations fluctuate less than the SPF long-term inflation expectations (see also Table 2).

\section{Inflation risks}

We have argued that the ECB's SPF inflation expectations bring in useful additional information to estimate the term structure of inflation expectations embodied in nominal yields, and, thereby, also the term structure of inflation risk premia. An important feature of the ECB's SPF is that, in addition to the standard point predictions, it also requests probability forecasts. Specifically, as for the more widely-used US SPF currently run by the Federal Reserve Bank of Philadelphia, survey panelists assign probabilities to the forecast variable falling into pre-specified ranges, i.e. a density forecast in the form of a histogram. As part of the published survey results, every survey round, the probability forecast (histogram) reported by each panelist are aggregated to construct a combined probability forecast that reflects the average probability assigned to each interval. Moreover, forecasters provide such density forecasts over three different horizons of 12-month ahead, 24-month ahead and five-years ahead, de facto providing a term structure of perceived inflation risks. This section presents the main characteristics of such inflation risks.

\subsection{Measuring inflation risks}

The SPF histograms do not provide direct measures of forecasters' inflation expectations and perceived risks. To estimate them, we fit a continuous density to the SPF histograms and estimate its key moments using the methodology introduced in Garcia and Manzanares (2007). Appendix B describes our estimation approach. Specifically, we estimate two key metrics of risks, namely the degree of inflation uncertainty surrounding the point prediction and the perceived asymmetry (skewness) in the inflation 
risks at each horizon. As proxy for market's perceptions of inflation risks we here focus on the key moments of the combined probability forecast. Such a probability forecast by construction averages the subjective perceptions of inflation risks of the individual forecasters and it is therefore more likely to represent the perceptions held in the market as a whole.

As regards the uncertainty surrounding inflation expectations, the second moment of the combined density forecast is a natural measure of the dispersion surrounding the consensus forecast. Recent work on SPF data has however stressed that the moments of the combined density are not the only possible measure of aggregated inflation risks, so as sensitivity analysis we also consider measures directly based on the moments of the individual probability forecasts. Specifically, by construction, the variance of the combined probability forecast incorporates not only the average uncertainty surrounding the individual forecasts but also the disagreement with respect to the expected mean inflation expectations across panelists. ${ }^{12}$ For this reason we also consider a more direct measure of the average uncertainty calculated by averaging the uncertainty in the individual probability forecasts.

Regarding asymmetries in perceived inflation risks, as sensitivity analysis we consider two measures of asymmetry. First, the skewness of the combined density forecast, calculated as the (normalized) third centred moment. ${ }^{13}$ Second, we consider the distance between the mean and the mode of the combined density forecast, which is also widely-used to assess the asymmetry of the density forecast regularly published by some major central banks in the form of fan-charts (see Blix and Sellin, 1998, and Britton et al. ,1998).

\footnotetext{
${ }^{12}$ We measure inflation uncertainty by the variance rather than the standard deviation because, by construction, the link between the aggregate variance and the average of individual variances that does not hold for the standard deviations. Specifically Agg. variance $=$ Average Uncertainty + Disagreement, with average uncertainty being the main component of the variance of the combined probability forecasts. See Garcia and Manzanares (2007) and references therein for details.

${ }^{13}$ The skewness of the combined probability forecast cannot be proxied by the skewness of the individual means nor by the average skewness across panelists (Garcia and Manzanares, 2007).
} 


\subsection{Perceived inflation risks in the euro area}

This section describes the main characteristics of inflation risks in the euro area. To get an idea of what the key moments of inflation forecasts can tell us about developments in inflation expectations and risks over time, Table 7 reports the correlations among the risk measures discussed above, as well as with actual inflation figures, the only observable state in our term structure model, and with the rate of growth of HICP excluding energy and unprocessed food ('core' inflation henceforth). For completeness the main diagonal of Table 6 also displays, within brackets, the standard deviation of those risk measures. The main insights for that information are as follows.

First, short-term (one year ahead) inflation expectations are strongly correlated (0.8) with overall HICP inflation, but much less so with core inflation (0.2). Such a correlation however weakens with horizon, and long-term (five years ahead) inflation expectations correlate neither with actual inflation (0.3) nor with core inflation (0.0). This evidence underscores the need to incorporate further information beyond actual inflation developments to identify long-term inflation expectations. Second, our inflation risk measures are little correlated with mean inflation expectations or actual inflation rates, both at short and long horizons, which suggests that inflation risks contain additional information beyond the central tendency of inflation expectations. Only average uncertainty shows some significant correlation with core inflation (0.7 at the two year and 0.5 at the five year horizons), but not to headline inflation (0.4 and 0.1 respectively). To the extent that core inflation can be interpreted as an underlying trend of inflationary pressures, these correlations suggest that it is not the (noisy) monthly movements in inflation but the smoother, underlying trend of inflation which drives inflation uncertainty.

Finally, the comovement between measures of inflation risks also leaves some interesting insights. Our two inflation uncertainty measures are positively correlated, but, as argued before, given the fact that they reflect different information that is directly related to the forecasters' disagreement about mean inflation expectations, that 
comovement is limited (see Table 7). In terms of the correlations between short and longer-term risk measures, there is a substantial difference between uncertainty and the balance of risks. Inflation uncertainty at short and long-term horizons shows a great deal of comovement, particularly when we use our average uncertainty measure. In contrast, the balance of risks surrounding short and longer term inflation forecasts reflects clearly different factors. In particular, perceived asymmetries in long-term inflation risks are not strongly influenced by other changes in inflation expectations.

We are particularly interested in the link between inflation risks and inflation risk premium over long horizons, so we describe now in some detail the dynamics of longterm inflation risks over the 1999Q1-2006Q4 period. Long-term inflation uncertainty has been, overall, relatively stable for most of the ECB era (see Figure 4). After remaining quite low between 1999 and 2001, in line with the gradual increase in inflation readings, inflation uncertainty rose steadily between 2001 and 2003, and remained at relatively high levels for about eight quarters, until around mid-2005. Reflecting the correlation between core inflation and long-term inflation uncertainty (see Table 7), once euro area core inflation fell consistently below the $2 \%$ mark, and despite that some further spikes in oil prices and other negative price shocks that pushed-up temporarily headline inflation readings, inflation uncertainty gradually declined.

Changes in the perceived balance of risks surrounding long-term inflation expectations have been instead more significant, including changes in sign and protracted downward and upward trends (see Figure 5). Between early 2000 and mid-2002 risks to long-term inflation expectations were perceived on the upside, what appears to signal some tensions in a level of (mean) long-term inflation expectations that remained slightly below $1.9 \%$. Between end-2001 and end-2004 the level of long-term inflation expectations rose slightly and fluctuated within the 1.90-1.95\% range, and associated upside risks diminished gradually, to the extent that from early 2003 downside risks dominate the distribution of long-term inflation risks. Early 2005 however marked the beginning of a new period for long-term inflation expectations, since both (mean) infla- 
tion expectations move closer to $2 \%$, and inflation risks associated with those inflation expectations were predominantly on the upside.

\section{$5 \quad$ Interpreting developments in inflation risk premia}

We seek for the link between the inflation risks perceived by macroeconomic forecasters and the inflation risk premia embodied in the term structure of interest rates. Our conjecture is that, to the extent that the perceived inflation risks embodied in the SPF density forecasts reflect those perceived by all economic agents in general and by market participants in particular, our measures of inflation risks should provide information about the pricing of inflation risks in bond yields. Survey-based inflation risk measures should therefore help interpret changes in the inflation risk premia. This section provides some evidence corroborating that conjecture.

There are however some caveats to bear in mind regarding the link between the inflation risks and inflation risk premia. First, from a modelling perspective, our estimates of inflation risk premia come from a Gaussian framework. The evidence presented in the previous section however suggests that perceived inflation risks exhibit some, albeit limited, time variation over the last few years, and marked features, like skewness, that are in contradiction with such model assumptions. Handling those inconsistencies is however beyond the scope of this paper. Our working hypothesis is that the Gaussian framework provides a reasonable and useful approximation that necessarily abstracts from some of the complexities of the actual data. Our aim here is to assess the extent to which, by combining information from our model and the SPF probability forecasts we can better interpret the dynamics of the inflation risk premia.

Second, from a conceptual perspective, the SPF density forecasts reflect the marginal probability distribution of inflation. Arguably, risk measures directly relevant to bond market participants would be based on the joint probability distribution of inflation and bond yields, but we believe that our inflation risk measures offer important new insights. 
Finally, from a statistical perspective, there is a mismatch in the frequency of the survey information (the SPF is carried out at quarterly frequency) and our model estimates (monthly). Since perceived inflation risks do not exhibit abrupt changes (see Figures 5 and 6 ) the frequency mismatch should not prevent the comparison to be meaningful.

Table 8 reports the correlations between the inflation risk premia and perceived inflation risks. We consider one year forward inflation risk premia ending in one, two and five years, and two measures of uncertainty (average uncertainty and the variance of the combined distribution) and asymmetry (skewness and the mean-mode distance).

As regards inflation uncertainty measures, the higher the uncertainty about future inflation, in theory, the higher the risks to hedge, and, other things equal, the higher should be the risk premia requested by investors. A positive correlation should therefore be expected. Indeed, short-term premia positively correlates with average uncertainty surrounding one year ahead and also over the longer horizon of two years ahead, but it is little correlated with inflation uncertainty over more distant horizons. In contrast, when inflation uncertainty is measured by the variance of the combined probability forecast, the correlation weakens and even turns negative, which highlights the importance of the measure of inflation uncertainty to choose.

The relationship between medium-to-long term premia and inflation uncertainty however poses a greater puzzle: the strong negative correlation is somewhat counterintuitive. On the one hand, it could be argued that this result reflects the relatively short sample available for the euro area, just seven years of data, and a period of "learning" about forecasting euro area data and a new monetary policy regime. On the other hand, the result appears to be quite robust: it holds for inflation risk premia at medium-to-long maturities as well as for different measures of inflation uncertainty. These results suggest that the dynamics of inflation risk premia in euro area market does not seem to reflect much changes in inflation uncertainty, at least over the narrow ranges observed in euro area data. 
Asymmetries in the perceived inflation risks instead seems to contain crucial information to interpret developments in the premia, particularly at longer horizons. Positive inflation skewness indicates that the risk of high inflation is perceived to be higher than that of lower inflation. Investors perceiving those risks for inflation therefore face higher probability that their nominal assets may loose value than otherwise if inflation turns out to be different from their baseline expectation. Other things equal, it is logical that investors then request a higher premia to hold those nominal assets. Consistent with this intuition, risk asymmetry measures at long horizons are positively correlated with the inflation risk premia.

Figure 6 further illustrates the potential of asymmetries in inflation risks and the inflation risk premia. The comovement between the two series is indeed striking, and changes in the asymmetry in perceived inflation risks seem even capable of most of the turning points in their dynamics. This evidence suggests that accounting for the perceived asymmetries in inflation risks is an important factor to understand movements in inflation risk premia.

Table 9 provides further statistical evidence on the information content of perceived asymmetries in inflation risks on the dynamics of inflation risk premia. First, to gauge the statistical significance of the correlations shown in Table 8 and Figure 6, a bivariate regression corroborates the strong significance of inflation skewness (see Column 1). Second, Columns 2-6 assess the robustness of that significance after controlling for several macroeconomic and financial factors that have been employed to interpret the dynamics of inflation risk premia in recent literature (e.g. Gürkaynak et al., 2009, Ciccarelli and Garcia, 2009). ${ }^{14}$ Specifically, inflation skewness remains strongly significant after controlling for inflation pressures (overall and core inflation, Column 2). Moreover, significance holds when controlling for the volatility of both core and headline inflation, as well as indicators of inflation pressures at earlier stages of the pricing chain (wages, PPI). Results adding indicators of economic activity are however mixed:

\footnotetext{
${ }^{14}$ Length considerations led us to report only selected results in Table 8. Additional results discussed in the text are available upon request.
} 
significance holds for the unemployment rate (see Column 3) and also industrial production, but not for a standard measure of the output gap (Column 4). The results for the output gap measure should be however interpreted with some caution, as they are not robust to the inclusion of additional factors in the regression (see also Columns 7 and 9). Inflation skewness' significance also holds when controlling for confidence indicators (consumer confidence, see Column 5, and also industrial confidence and the PMI index) as well as financial indicators (the slope of the yield curve and the volatility in the bond and stock markets) usually employed as proxies for financial market risk. Furthermore, the asymmetry in inflation risks remains strongly significant even if controlling simultaneously for all the inflation, economic activity, confidence and financial indicators considered before (see Column 7). Finally, Columns 8 and 9 show that our main finding is also robust to an alternative measure of the asymmetry in inflation risks based on the distance between the mean and the mode of the inflation density forecast over long-term horizons.

The statistical evidence reported in Table 9 further underpins the information content of perceived asymmetries in inflation risks for the dynamics of inflation risk premia over long horizons. We showed that the relevance of our survey inflation risk measure is little affected by considering a large number of macroeconomic and financial factors that should determine inflation risk premia. Moreover, standard regressions along the lines of those in Table 9 corroborate the Table 8 results that it is the asymmetry in inflation risks and not the inflation uncertainty over long horizons what markets seem to price.

\section{Concluding remarks}

We investigated the link between the inflation risks in macroeconomic forecasts and the inflation risk premia embodied in the term structure of interest rates in the euro area. To that end, we first provided stylized facts about both the term structure of inflation risk premia and perceived inflation risks in the euro area. Specifically, using 
a no-arbitrage term structure model built along the lines of Ang, Bekaert and Wei (2008) and D'Amico, Kim and Wei (2007) for the US term structure we document some stylized facts about the term structure of inflation compensation, inflation expectations and inflation risk premia in the euro area bond market. Using the inflation density forecasts from the ECB's Survey of Professional Forecasters, we present new quantitative evidence on the degree of uncertainty and balance of risks surrounding those inflation forecasts at different horizons. We then documented some stylized facts of that term structure of inflation risks over the first eight years of the euro area.

The novelty of our analysis stems from using the inflation risks to interpret the dynamics of inflation risk premium. Latent factor models like ours fit data well, but are often criticized for lacking economic interpretation. Our main finding is that the dynamics of long-term inflation risk premia mimics that of the perceived asymmetries of inflation risks. Indeed, our results suggest that it is the perceived balance of risks, and not the inflation uncertainty, which seems to be crucial to understand the dynamics of inflation risk premia. We also show that the explanatory power of the asymmetries in inflation risks is robust, and holds after controlling for a large number of macroeconomic and financial factors that capture inflationary pressures, business cycle and confidence indicators as well as standard risk indicators in financial markets.

To our knowledge, this is the first attempt to bring together forecast risk measures, mainly based on macroeconomic data, and inflation risk premia, mainly based on financial data. This paper therefore extended the recent use of survey data in term structure modelling beyond the point predictions, and we believe that our findings open new avenues to explore in terms of inflation expectation formation, bond pricing and term structure modelling.

From the point of view of inflation expectation analysis, our findings suggest that further work on the determinants of inflation risks would be welcome, not only to improve our understanding of expectation formation in general but also the role of higher-order moments of inflation expectations in other areas like asset pricing. In- 
deed, we showed that at short horizons inflation uncertainty helps explain inflation risk premium, but at longer horizons the dynamics of inflation risk premia reflects the balance of inflation risks, which suggest that markets price in the asymmetries in inflation risks rather than their spread. Among the potential explanations for our findings, the fact that central bank communication, and also media and market participants, increasingly stress the role of inflation risks in general and upside inflation risks in particular for monetary policy decisions may be behind that relationship. In any case, explaining further the forces at work leading to our main finding can be an important topic of research for theoretical models of asset pricing.

From the perspective of term structure modelling, our findings also suggest that there is much information in survey-based inflation risks beyond that included in standard term structure models. Such information is very useful for the modelling of the term structure of interest rates and its interpretation. Our results may offer a new avenue to combine macroeconomic and financial information without the need to impose the potentially controversial restrictions of a fully-fledged macroeconomic model on the term structure. In addition, the stylized facts about the perceived inflation risks that we report here could support new models capable of exploiting the non-Gaussian features of the inflation risks that we documented here to improve the efficiency in the estimation of term structure models. Moving beyond a Gaussian framework while retaining the tractability and interpretability of term structure models is likely to be quite challenging, but it opens a wide range of new possibilities for term structure modelling that we hope can be explored in a near future. 


\section{Appendix}

\section{A Model details}

\section{A.1 Bond prices}

\section{A.1.1 Real bond prices}

The price of a one-period real bond $\hat{P}_{t}^{1}$ in time $t$ is the expected value of the pricing kernel in time $t+1$

$$
\hat{P}_{t}^{1}=E_{t}\left(\hat{M}_{t+1}\right)
$$

Substituting the pricing kernel (stochastic discount factor) by $-r_{t}-\frac{1}{2} \lambda_{1}^{\prime} \lambda_{t}-\lambda_{t}^{\prime} \epsilon_{t+1}$ and applying basic properties of the normal distribution ${ }^{15}$ we get

$$
\hat{P}_{t}^{1}=E_{t}\left(\exp \left(-r_{t}-\frac{1}{2} \lambda_{1}^{\prime} \lambda_{t}-\lambda_{t}^{\prime} \epsilon_{t+1}\right)\right)=\exp \left(-r_{t}\right)=\exp \left(-\delta_{0}-\delta_{1}^{\prime} X_{t}\right)
$$

Comparing this equation with the exponentially affine pricing equation $\hat{P}_{t}^{1}=\exp \left(\hat{A}_{1}+\right.$ $\left.\hat{B}_{1}^{\prime} X_{t}\right)$ gives the starting values for the recursive computation of the factor loadings $\hat{A}_{1}=-\delta_{0}$ and $\hat{B}_{1}^{\prime}=-\delta_{1}$.

In general, the price of a $n+1$ maturity bond in time $t$ is the expected value of the (stochastically) discounted price of the same bond at time $t+1$ value of a maturity $n$ bond

$$
\hat{P}_{t}^{n+1}=E_{t}\left(\hat{M}_{t+1} \hat{P}_{t+1}^{n}\right) .
$$

Substituting the definition of the pricing kernel and applying the exponentially affine pricing rule gives

$$
\hat{P}_{t}^{n+1}=E_{t}\left[\exp \left(-r_{t}-\frac{1}{2} \lambda_{1}^{\prime} \lambda_{t}-\lambda_{t}^{\prime} \epsilon_{t+1}\right) \exp \left(\hat{A}_{n}+\hat{B}_{n}^{\prime} X_{t+1}\right)\right] .
$$

\footnotetext{
${ }^{15}$ If $X$ is a normal distributed random variable, $Y=e^{x}$ is log-normal distributed with $E(Y)=$ $e^{E(x)+\frac{1}{2} \operatorname{Var}(x)}$.
} 
Substitution further for $X_{t+1}$ and rearranging gives

$$
\begin{aligned}
\hat{P}_{t}^{n+1} & =E_{t}\left[\exp \left(-r_{t}-\frac{1}{2} \lambda_{1}^{\prime} \lambda_{t}-\lambda_{t}^{\prime} \epsilon_{t+1}+\hat{A}_{n}+\hat{B}_{n}^{\prime}\left(\mu+\Phi X_{t}+\Sigma \epsilon_{t+1}\right)\right)\right] \\
& =\exp \left(-r_{t}-\frac{1}{2} \lambda_{1}^{\prime} \lambda_{t}+\hat{A}_{n}+\hat{B}_{n}^{\prime}\left(\mu+\Phi X_{t}\right)\right) E_{t}\left[\exp \left(\left(\hat{B}_{n}^{\prime} \Sigma-\lambda_{t}^{\prime}\right) \epsilon_{t+1}\right)\right] .
\end{aligned}
$$

Using properties of the normal distribution gives ${ }^{16}$

$$
\hat{P}_{t}^{n+1}=\exp \left(-r_{t}-\frac{1}{2} \lambda_{1}^{\prime} \lambda_{t}+\hat{A}_{n}+\hat{B}_{n}^{\prime}\left(\mu+\Phi X_{t}\right)+\frac{1}{2}\left(\hat{B}_{n}^{\prime} \Sigma-\lambda_{t}^{\prime}\right)\left(\hat{B}_{n}^{\prime} \Sigma-\lambda_{t}^{\prime}\right)^{\prime}\right)
$$

Using the affine pricing rule $\hat{P}_{t}^{n+1}=\exp \left(\hat{A}_{n+1}+\hat{B}_{n+1}^{\prime} X_{t}\right)$ on the right side of this equation and substituting for the market price of risk $\lambda_{t}=\lambda_{0}+\lambda_{1} X_{t}$ and the short rate $r_{t}=-\delta_{o}-\delta_{1}^{\prime} X_{t}$ gives

$$
\begin{aligned}
\exp \left(\hat{A}_{n+1}+\hat{B}_{n+1}^{\prime} X_{t}\right)= & \exp \left(-\delta_{0}+\hat{A}_{n}+\hat{B}_{n}^{\prime}\left(\mu-\Sigma \lambda_{0}\right)+\frac{1}{2} \hat{B}_{n} \Sigma \Sigma \hat{B}_{n}^{\prime}\right. \\
& \left.+\left(\hat{B}_{n}^{\prime}\left(\Phi-\Sigma \lambda_{1}\right)-\delta_{1}^{\prime}\right) X_{t}\right)
\end{aligned}
$$

Equating the constant terms and the terms multiplied by $X_{t}$ on both sides of this equation gives

$$
\begin{aligned}
& \hat{A}_{n+1}=-\delta_{0}+\hat{A}_{n}+\hat{B}_{n}^{\prime}\left(\mu-\Sigma \lambda_{0}\right)+\frac{1}{2} \hat{B}_{n} \Sigma \Sigma \hat{B}_{n}^{\prime} \\
& \hat{B}_{n+1}^{\prime}=-\delta_{1}^{\prime}+\hat{B}_{n}^{\prime}\left(\Phi-\Sigma \lambda_{1}\right)
\end{aligned}
$$

\section{A.1.2 Nominal bond prices}

Nominal bonds are priced by using the nominal pricing kernel $M_{t+1}$ instead of the real pricing kernel. Both pricing kernels are linked by inflation $M_{t+1}=\hat{M}_{t+1} / \Pi_{t+1}$. This implies for the log pricing kernel ${ }^{17} m_{t+1}=\log \left(M_{t+1}\right)=\hat{m}_{t+1}-\pi_{t+1}$.

\footnotetext{
${ }^{16}$ Note that $\Sigma$ is symmetric, that is $\Sigma^{\prime}=\Sigma$.

${ }^{17}$ Using $\pi_{t+1}=\log \left(\Pi_{t+1}\right)$ and $\hat{m}_{t+1}=\log \left(\hat{M}_{t+1}\right)$
} 
Using the definition of the real pricing kernel and the fact that inflation $\pi_{t}$ is included in the state vector ${ }^{18}$ the log nominal pricing kernel can be written as

$$
m_{t+1}=-r_{t}-\frac{1}{2} \lambda_{1}^{\prime} \lambda_{t}-\lambda_{t}^{\prime} \epsilon_{t+1}-e_{N}^{\prime} X_{t+1}
$$

In the next step, the price of a one-period nominal bond can be computed by

$$
P_{t}^{1}=\exp \left(A_{1}+B_{1} X_{t}\right)=E_{t}\left[\exp \left(-r_{t}-\frac{1}{2} \lambda_{1}^{\prime} \lambda_{t}-\lambda_{t}^{\prime} \epsilon_{t+1}-e_{N}^{\prime} X_{t+1}\right)\right]
$$

Substituting for $r_{t}$ and $X_{t+1}$ and rearranging terms gives

$$
\begin{aligned}
\exp \left(A_{1}+B_{1} X_{t}\right) & =E_{t}\left[\exp \left(-\delta_{0}-\left(\delta_{1}^{\prime}+e_{N}^{\prime} \Phi\right) X_{t}-\frac{1}{2} \lambda_{1}^{\prime} \lambda_{t}-e_{N}^{\prime} \mu-\left(\lambda_{t}^{\prime}+e_{N}^{\prime} \Sigma\right) \epsilon_{t+1}\right)\right] \\
& =\exp \left(-\delta_{0}-\left(\delta_{1}^{\prime}+e_{N}^{\prime} \Phi\right) X_{t}-\frac{1}{2} \lambda_{1}^{\prime} \lambda_{t}-e_{N}^{\prime} \mu\right) E_{t}\left[\exp \left(-\left(\lambda_{t}^{\prime}+e_{N}^{\prime} \Sigma\right) \epsilon_{t+1}\right)\right]
\end{aligned}
$$

Solving the expectations term and substituting for $\lambda_{t}$ we get ${ }^{19}$

$$
\exp \left(A_{1}+B_{1} X_{t}\right)=\exp \left(-\delta_{0}-\left(\delta_{1}^{\prime}+e_{N}^{\prime} \Phi\right) X_{t}-e_{N}^{\prime} \mu+\frac{1}{2} e_{N}^{\prime} \Sigma \Sigma e_{N}+e_{N}^{\prime} \Sigma \lambda_{0}+e_{N}^{\prime} \Sigma \lambda_{1} X_{t}\right)
$$

Equating constant terms and terms multiplied by $X_{t}$ on both sides gives

$$
\begin{aligned}
& \left.A_{1}=-\delta_{0}-e_{N}^{\prime} \mu+\frac{1}{2} e_{N}^{\prime} \Sigma \Sigma e_{N}+e_{N}^{\prime} \Sigma \lambda_{0}\right) \\
& B_{1}^{\prime}=e_{N}^{\prime} \Sigma \lambda_{1}-\left(\delta_{1}^{\prime}+e_{N}^{\prime} \Phi\right)
\end{aligned}
$$

In general, similar to the case of real bond prices, we have

$$
\begin{aligned}
P_{t}^{n+1}=\exp \left(A_{n+1}+B_{n+1}^{\prime} X_{t}\right)=E_{t}\left[\operatorname { e x p } \left(-\delta_{0}+\delta_{1}^{\prime} X_{t}\right.\right. & -\frac{1}{2} \lambda_{1}^{\prime} \lambda_{t}-\lambda_{t}^{\prime} \epsilon_{t+1} \\
& \left.\left.-e_{N}^{\prime} X_{t+1}+A_{n}+B_{n}^{\prime} X_{t+1}\right)\right] .
\end{aligned}
$$

\footnotetext{
${ }^{18}$ As inflation $\pi_{t}$ is the last variable in the state vector $X_{t}$ which is of dimension $N$ and the vector $e_{N}$ (which contains only zeros with the exception of the element $N$ which is one) can be used to extract $\pi$ from the state vector.

${ }^{19}$ We use the relationship $\left(\lambda_{t}^{\prime}+e_{N}^{\prime} \Sigma\right)\left(\lambda_{t}^{\prime}+e_{N}^{\prime} \Sigma\right)^{\prime}=\left(\lambda_{t}^{\prime}+e_{N}^{\prime} \Sigma\right)\left(\Sigma^{\prime} e_{N}+\lambda_{t}\right)=e_{N}^{\prime} \Sigma \Sigma e_{N}+\lambda_{t}^{\prime} \lambda_{t}+2 e_{N}^{\prime} \Sigma \lambda_{t}$.
} 
After substituting for $X_{t+1}$ we get

$$
\begin{aligned}
\exp \left(A_{n+1}+B_{n+1}^{\prime} X_{t}\right) & =E_{t}\left[\operatorname { e x p } \left(-\delta_{0}+\delta_{1}^{\prime} X_{t}-\frac{1}{2} \lambda_{1}^{\prime} \lambda_{t}+\left(\left(B_{n}^{\prime}-e_{N}^{\prime}\right) \Sigma-\lambda_{t}^{\prime}\right) \epsilon_{t+1}\right.\right. \\
& \left.\left.+A_{n}+\left(B_{n}^{\prime}-e_{N}^{\prime}\right) \mu+\left(B_{n}^{\prime}-e_{N}^{\prime}\right) \Phi X_{t}\right)\right] .
\end{aligned}
$$

Solving for the expectation term ${ }^{20}$ and substituting for $\lambda_{t}$ gives after rearrangements

$$
\begin{aligned}
& \exp \left(A_{n+1}+B_{n+1}^{\prime} X_{t}\right)=\exp \left[-\delta_{0}+A_{n}+\left(B_{n}-e^{\prime} N\right)\left(\mu-\Sigma \lambda_{0}\right)\right. \\
& \left.\quad+\frac{1}{2}\left(B_{n}-e^{\prime} N\right) \Sigma \Sigma\left(B_{n}-e^{\prime} N\right)+\left(\left(B_{n}-e^{\prime} N\right) \Phi-\delta_{1}^{\prime}-\left(B_{n}-e^{\prime} N\right) \Sigma \lambda_{1}\right) X_{t}\right] .
\end{aligned}
$$

Again, after equating constant terms and terms multiplied by $X_{t}$ on both sides of the equation we get

$$
\begin{aligned}
& A_{n+1}=-\delta_{0}+A_{n}+\left(B_{n}^{\prime}-e_{N}^{\prime}\right)\left(\mu-\Sigma \lambda_{0}\right)-\frac{1}{2}\left(B_{n}^{\prime}-e_{N}^{\prime}\right) \Sigma \Sigma\left(B_{n}^{\prime}-e_{N}^{\prime}\right)^{\prime} \\
& B_{n+1}^{\prime}=\left(B_{n}^{\prime}-e_{N}^{\prime}\right)\left(\Phi-\Sigma \lambda_{1}\right)-\delta_{1}^{\prime}
\end{aligned}
$$

\section{A.2 The state-space form of the model}

In order to use Kalman filter estimation techniques, we first express the affine term structure model in a state-space form:

$$
\begin{array}{ll}
w_{t}=d+Z X_{t}+\eta_{t} & \text { (measurement equation) } \\
X_{t}=\Phi X_{t-1}+\Sigma \epsilon_{t} & \text { (state equation). }
\end{array}
$$

The vector $d$ and the matrix $Z$, which link the state variables (latent factors) with the observed data, are constructed by using the coefficients $\hat{A}_{n}, \hat{B}_{n}^{\prime}, A_{n}$, and $B_{n}^{\prime}$ described in section A.1. The transformations of the bond prices into bond yields are done by using the relation $P_{t}^{n}=\exp \left(-y_{t}^{n} n\right)$ or $y_{t}^{n}=-\log \left(P_{t}^{n}\right) / n$.

\footnotetext{
${ }^{20}$ We use the relationship $\left.\left(\left(B_{n}^{\prime}-e_{N}^{\prime}\right) \Sigma-\lambda_{t}^{\prime}\right)\left(\left(B_{n}^{\prime}-e_{N}^{\prime}\right) \Sigma-\lambda_{t}^{\prime}\right)^{\prime}=\left(B_{n}^{\prime}-e_{N}^{\prime}\right) \Sigma-\lambda_{t}^{\prime}\right)\left(-\lambda_{t}+\Sigma\left(B_{n}^{\prime}-e_{N}^{\prime}\right)^{\prime}\right)=$ $\lambda_{t}^{\prime} \lambda_{t}+\left(B_{n}^{\prime}-e_{N}^{\prime}\right) \Sigma \Sigma\left(B_{n}^{\prime}-e_{N}^{\prime}\right)^{\prime}-2\left(B_{n}^{\prime}-e_{N}^{\prime}\right) \Sigma \lambda_{t}$
} 
The vector of observed data $w_{t}$ contains the bond yields and, if the model includes them, the SPF inflation expectations:

$$
\mathbf{w}_{t}=\left[\begin{array}{c}
y_{t}^{3} \\
y_{t}^{12} \\
y_{t}^{24} \\
y_{t}^{36} \\
y_{t}^{60} \\
\pi_{t} \\
\hat{y}_{t}^{24} \\
\hat{y}_{t}^{36} \\
\hat{y}_{t}^{60} \\
E_{t}^{\mathrm{SPF}}\left[\pi_{t+12}\right] \\
E_{t}^{\mathrm{SPF}}\left[\pi_{t+24}\right] \\
E_{t}^{\mathrm{SPF}}\left[\pi_{t+60}\right.
\end{array}\right] \quad \mathbf{d}=\left[\begin{array}{c}
-A_{3} / 3 \\
-A_{12} / 12 \\
-A_{24} / 24 \\
-A_{36} / 36 \\
-A_{60} / 60 \\
0 \\
-\hat{A}_{24} / 24 \\
-\hat{A}_{36} / 36 \\
-\hat{A}_{60} / 60 \\
e_{3}\left(I-\Phi^{12}\right)(I-\Phi)^{-1} \mu \\
e_{3}\left(I-\Phi^{24}\right)(I-\Phi)^{-1} \mu \\
e_{3}\left(I-\Phi^{60}\right)(I-\Phi)^{-1} \mu
\end{array}\right] \quad \mathbf{Z}=\left[\begin{array}{c}
-B_{3} / 3 \\
-B_{12} / 12 \\
-B_{24} / 24 \\
-B_{36} / 36 \\
-B_{60} / 60 \\
0 \\
-\hat{B}_{24} / 24 \\
-\hat{B}_{36} / 36 \\
-\hat{B}_{60} / 60 \\
e_{3} \Phi^{12} \\
e_{3} \Phi^{24} \\
e_{3} \Phi^{60}
\end{array}\right]
$$

The structure of the variance-covariance matrix of the measurement errors is as follows

$$
\left[\begin{array}{cccc}
\sigma_{\epsilon}^{2}(1) & 0 & \ldots & 0 \\
0 & \sigma_{\epsilon}^{2}(2) & \ldots & 0 \\
\vdots & \vdots & \ddots & \vdots \\
0 & 0 & \ldots & \sigma_{\epsilon}^{2}(12)
\end{array}\right]
$$

We impose the following restrictions in its main diagonal elements

$$
\begin{aligned}
\sigma_{\epsilon}^{2}(1), \ldots, \sigma_{\epsilon}^{2}(5) & =\tilde{\sigma}_{\epsilon}^{2}(1), \\
\sigma_{\epsilon}^{2}(6) & =0, \\
\sigma_{\epsilon}^{2}(7), \ldots, \sigma_{\epsilon}^{2}(9) & =\tilde{\sigma}_{\epsilon}^{2}(2), \\
\sigma_{\epsilon}^{2}(10), \ldots, \sigma_{\epsilon}^{2}(12) & =\tilde{\sigma}_{\epsilon}^{2}(3),
\end{aligned}
$$


which implies that (i) inflation $\pi_{t}$ is measured without error; (ii) data freely determines the variances of the measurement errors for nominal yields, real yields and survey inflation expectations. The transition equation of the state-space is identical to the transition equation described in the main text.

\section{B Measuring inflation expectations and inflation risks}

As for the more widely-used US SPF currently run by the Federal Reserve Bank of Philadelphia, survey panelists of the ECB's SPF assign probabilities to future inflation falling into pre-specified ranges, i.e. a density forecast in the form of a histogram. Every survey round, the density forecast (histogram) reported by each panelist are aggregated to construct a combined density forecast, which reflects the average probability assigned to each interval.

We interpret those SPF histograms as a discretized version of a continuos density forecast. The probabilities assigned to each survey interval should therefore correspond to the integrals of the underlying density function over each of the pre-specified intervals $\left(\alpha_{i-1}, \alpha_{i}\right), i=1, \ldots, I$, where $\alpha_{0}:=-\infty$, and $\alpha_{I}:=\infty$. In practice, however, it is unlikely that survey participants discretize their density forecasts by computing those integrals. As working hypothesis, we then assume that the discretization resembles a sampling experiment based on "draws" from their continuous density forecast. The reported probabilities reflect how many of those draws lie within each of the intervals, and therefore interpret the reported probabilities as the realization of a multinomial random variable with $I$ classes. In this framework, the observed frequencies $(\widehat{p})$ are a sufficient statistic for estimating the theoretical probabilities $\left(p\right.$, with $p_{i}$ denoting the probability mass of the theoretical density in the interval $\left.\left(\alpha_{i-1}, \alpha_{i}\right)\right)$.

Our inference problem is to find the parameter vector $\varrho$ that defines the theoretical density function by matching the reported frequencies of the SPF histograms. In this context, least squares, the fitting criterion usually employed in existing lit- 
erature on SPF data, is not efficient. ${ }^{21}$ In search for an efficient criterion, following Cressie and Read (1988), we use a small departure from maximum likelihood estimation within the family of "power divergence estimators".22 Indexed by the parameter $\tau \in R$, that family is defined as the estimators obtained by minimizing $I^{\tau}(\widehat{p}, p)=[1 / \tau(\tau+1)] \sum_{i=0}^{I}\left[\widehat{p}_{i}\left[\widehat{p}_{i} / p_{i}(\varrho)\right]^{\tau}-1\right]$ with respect to $\varrho$. While exhibiting optimal large sample properties, more robust power distance estimators underperform with respect to maximum likelihood estimation in terms of efficiency in small samples (in the multinomial framework, a small number of draws to discretize the density forecast and report the SPF histogram). Within that family of estimators, the researcher can choose an efficient fitting criterion by taking into account the small sample properties of the power divergence estimators and the characteristics of the SPF data. Specifically, an inspection of the SPF data suggests that (numerical) robustness to inliers (i.e. intervals with much lower observed probability than the theoretical density suggests, for example related to rounding) is fundamental. Monte Carlo simulations specifically designed to match those particularities of the SPF data confirm that a small departure from maximum likelihood estimation (that is, a positive but relatively low value of the parameter $\tau(\tau=0.2))$ is optimal for the SPF data (see Cressie and Read, 1988, Lindsay, 1994, and Garcia and Manzanares, 2007).

As underlying density we employ a potentially skewed distribution, Azzalini's (1985) skew-normal family. Skewness is a crucial feature of any forecast. For example, in the Bank of Sweden's or the Bank of England's "fan charts", skewness plays a prominent role, and central bank official statements often include references to the "assessment of risks".

The Skew-Normal class $S N\left(\lambda_{s n}\right)$ is built by shifting and re-scaling a standard distribution with density function defined as $f_{\lambda_{s n}}(z):=2 \varphi_{n}(z) \Phi\left(\lambda_{s n} z\right), z \in \mathbb{R}$, where $\varphi_{n}$

\footnotetext{
${ }^{21}$ Although widely-used to fit densities to the SPF histograms (first advocated in Giordani and Söderlind, 2003), the least squares criterion (although consistent) is not efficient: it assigns equal weight to the fitting errors for each interval, while an efficient criterion would weight fitting errors differently according to the probability assigned to each interval to improve the estimation.

${ }^{22}$ The Pearson and the Neyman Chi-Square criteria, the Hellinger distance, and the Kullbach-Leibler divergence belong to this family of estimators, and maximum likelihood is a limiting case when $\tau \rightarrow 0$.
} 
and $\Phi_{n}$ are the standard normal density and distribution functions, respectively, and $\lambda_{s n} \in R$ is the shape parameter. If $\lambda_{s n}=0$, the standard Skew-Normal is just the standard normal, so using the $S N$ we do not impose any ex-ante restriction on the shape of the density underlying the SPF histograms and let the data speak about the presence of asymmetries in them.

A general random variable $W$ is skew-normal distributed if it can be written as

$$
W=\mu+\sigma\left(\frac{Z-E[Z]}{\sqrt{V(Z)}}\right) \quad Z \sim S N\left(\lambda_{s n}\right)
$$

The first three central moments of $Y$ are then expressed as $E[W]=\mu ; V(W)=\sigma^{2}$ and $S K(W)=\gamma_{1}=\left(2 b_{s n}^{2}-1\right) b_{s n} \kappa^{3} /\left(1-b_{s n}^{2} \kappa^{2}\right)^{3 / 2}$, where $b=\sqrt{2 / \pi}$ and $\kappa=\lambda_{s n} / \sqrt{\left(1+\lambda_{s n}^{2}\right)}$.

Monte Carlo evidence confirms that these two methodological contributions, namely our fitting criterion and the skew-normal density, lead to significant accuracy gains in the estimation of the key moments of the SPF histograms. ${ }^{23}$

\footnotetext{
${ }^{23}$ See Garcia and Manzanares (2007) for details.
} 


\section{References}

[1] Ang, A., G. Bekaert and M. Wei (2007), Do Macro Variables, Asset Markets or Surveys Forecast Inflation Better?, Journal of Monetary Economics, 54, 11631212.

[2] Ang, A., G. Bekaert and M. Wei (2008), The Term Structure of Real Rates and Inflation Expectations, Journal of Finance, 63, p797-849.

[3] Ang, A. and M. Piazzesi (2003), A no-arbitrage vector autoregression of term structure dynamics with macroeconomic and latent variables, Journal of Monetary Economics, 50, 745-787.

[4] Azzalini, A. (1985), A Class of Distributions which Includes the Normal Ones, Scandinavian Journal of Statistics, 12, 171-178.

[5] Bekaert, G., S. Cho and A. Moreno (2009), New-Keynesian Macroeconomics and the Term Structure, Journal of Money, Credit and Banking, forthcoming.

[6] Bernanke, B. 2007, Inflation expectations and inflation forecasting, speech delivered at the Monetary Workshop of the NBER Summer Institute, Cambridge, MA.

[7] Blix, M. and P. Sellin, Uncertainty Bands for Inflation Forecasts, Sveriges Riksbank Working Paper Series 65, September, 1998.

[8] Britton, E., P. Fisher and J. Whitley, The Inflation Report Projections: Understanding the fan chart, Bank of England Quarterly Bulletin, February, 1998.

[9] Chernov, M., and P. Mueller (2008), The term structure of inflation expectations, CEPR Discussion Papers No. 6809.

[10] Chernozhukov, V. and H Hong (2003), An MCMC approach to classical estimation, Journal of Econometrics, 115, 293 - 346.

[11] Ciccarelli, M. and J.A. Garcia (2009), What drives euro area break-even inflation rates?, ECB Working Paper Series No. 996, January. See also revised and extended version, Inflation compensation and the macroeconomy: what drives break-even inflation rates, prepared for the NBER Summer Institute, July 2009.

[12] Cressie, N. and T.R.C. Read (1988), Goodness-of-fit statistics for discrete multivariate data, Springer Verlag, New York.

[13] Dewachter, H. and M. Lyrio (2006), Macro factors and the term structure of interest rates, Journal of Money, Credit, and Banking, 38, 119-140.

[14] Dewachter, H. and M. Lyrio (2008), Learning, Macroeconomic Dynamics and the Term Structure of Interest Rates, forthcoming in: Asset Pricing and Monetary Policy, John Campbell, ed.

[15] Ejsing, J., J.A. Garcia and T. Werner (2007), The term structure of euro area break-even inflation rates: the impact of seasonality, ECB Working Paper Series No. 830, November. 
[16] Garcia, J.A. (2003), An Introduction to the ECB's Survey of Professional Forecasters, ECB Occasional Paper, No. 8.

[17] Garcia, J.A. and A. Manzanares (2007), What can Probabilistic Forecasts tell us about Inflation Risks?, ECB Working Paper Series No. 825, October.

[18] Garcia , J.A., and A. van Rixtel (2007), Inflation-linked bonds from a Central Bank's Perspective, ECB Occasional Paper, No. 62, June

[19] Giordani, P., and P. Söderlind (2003), Inflation Forecast Uncertainty, European Economic Review, 47, 1037-1059.

[20] Hördahl, P. and O. Tristani (2007), Inflation risk premia in the term structure of interest rates, ECB Working Paper Series No. 734, February. Revised version prepared for the ECB workshop "Measuring and interpreting the inflation risk premia for monetary policy", Frankfurt, December 2007.

[21] Gürkaynak, R., A. Levin and E. Swanson (2009), Does inflation targeting anchor long-run inflation expectations? Evidence from long-term bond yields in the U.S., U.K., and Sweden, Journal of the European Economic Association, forthcoming.

[22] Joyce, M, P. Lildholdt, and S. Sorensen, 2009, Extracting inflation expectations and inflation risk premia from the term structure: a joint model of the UK nominal and real yield curves, Working paper No. 360, Bank of England.

[23] Kim, D. H. (2007), Challenges in Macro-Finance Modelling, BIS Working Paper, No. 240.

[24] Kozicki, S. and P.A. Tinsley (2001), Shifting Endpoints in the Term Structure of Interest Rates, Journal of Monetary Economics 47, 613-652.

[25] Lindsay, B.G. (1994), Efficiency versus Robustness: the Case for Minimum Hellinger Distance and Related Methods, The Annals of Statistics, 22, 10811114 .

[26] Mönch, E. (2008), Forecasting the Yield Curve in a Data-Rich Environment: A NoArbitrage Factor-Augmented VAR Approach, Journal of Econometrics, 146, $26-43$.

[27] Trichet, J.-C. ,2005, Monetary Policy and Private Expectations, Zolotas Lecture at the Bank of Greece, Athens, February, http://www.ecb.int/press/key/date/2005/html/. 
Table 1: Summary statistics of euro area yield curve data

\begin{tabular}{|c|c|c|c|c|c|c|c|}
\hline & \multicolumn{4}{|c|}{ Central moments } & \multicolumn{3}{|c|}{ Autocorrelation } \\
\hline & Mean & STDev. & Skew & Kurtosis & Lag 1 & Lag 2 & Lag 3 \\
\hline \multicolumn{8}{|l|}{ Euro area nominal yields } \\
\hline 1-year yield & 3,15 & 0,93 & 0,58 & $-0,69$ & 0,98 & 0,95 & 0,92 \\
\hline 2-year yield & 3,35 & 0,87 & 0,42 & $-0,96$ & 0,97 & 0,93 & 0,89 \\
\hline 5-year yield & 3,88 & 0,75 & 0,24 & $-1,14$ & 0,94 & 0,88 & 0,83 \\
\hline \multicolumn{8}{|l|}{ Euro area real yields } \\
\hline 2-year yield & 0,77 & 0,51 & 0,42 & $-1,07$ & 0,94 & 0,88 & 0,80 \\
\hline 5-year yield & 1,23 & 0,34 & $-0,34$ & $-1,02$ & 0,90 & 0,82 & 0,69 \\
\hline \multicolumn{8}{|l|}{ Euro area forward BEIRs } \\
\hline 1-year BEIR & 2,00 & 0,27 & 1,08 & $-0,69$ & 0,89 & 0,75 & 0,63 \\
\hline $\begin{array}{l}\text { 1-year forward BEIR ending } \\
\text { in two years }\end{array}$ & 1,99 & 0,15 & 0,37 & $-0,57$ & 0,95 & 0,87 & 0,78 \\
\hline $\begin{array}{l}\text { 1-year forward BEIR ending } \\
\text { in five years }\end{array}$ & 2,15 & 0,14 & 0,36 & $-0,70$ & 0,93 & 0,82 & 0,72 \\
\hline
\end{tabular}

Note: table statistics refer to monthly data over the period 1999M1-2006Q4. Nominal yields are zero coupons from Bloomberg ; real yields are zero-coupon adjusted for inflation seasonality as described in Ejsing et al. (2007), and their statistics refer to the period 2004M2-2006Q4; the calculation of forward break-even inflation rates ( inflation compensation), one of the contributions of this paper, is described in Section 2. 
Table 2: Parameter estimation (benchmark model including survey data)

\begin{tabular}{|c|c|c|c|}
\hline & \multirow[t]{2}{*}{ Estimated parameters } & \multicolumn{2}{|c|}{ 99\% Confidence bounds } \\
\hline & & lower bound & upper bound \\
\hline$\mu_{\pi} * 1200$ & 0.1570 & 0.0362 & 0.2088 \\
\hline$\Phi_{11}$ & 0.9591 & 0.8651 & 0.9993 \\
\hline$\Phi_{22}$ & 0.9592 & 0.9288 & 0.9999 \\
\hline$\Phi_{33}$ & 0.9206 & 0.8888 & 0.9849 \\
\hline$\Phi_{21}$ & 0.0896 & 0.0295 & 0.1903 \\
\hline$\Phi_{31} * 1200$ & 0.0022 & 0.0004 & 0.0138 \\
\hline$\Phi_{32} * 1200$ & -0.0023 & -0.0030 & -0.0001 \\
\hline$\sigma_{\pi} * 12 * 10^{5}$ & 0.0292 & 0.0055 & 0.0895 \\
\hline$\lambda_{0,1}$ & -0.3039 & -0.7257 & -0.0055 \\
\hline$\lambda_{0,2}$ & 0.4344 & 0.0690 & 0.7599 \\
\hline$\lambda_{1,11}$ & -0.0047 & -0.0102 & -0.0014 \\
\hline$\lambda_{1,12}$ & 0.0170 & 0.0078 & 0.0358 \\
\hline$\lambda_{1,21}$ & 0.0429 & 0.0037 & 0.0564 \\
\hline$\lambda_{1,22}$ & -0.0513 & -0.0639 & -0.0031 \\
\hline$\delta_{0} * 1200$ & 1.2243 & 1.2243 & 1.2243 \\
\hline$\delta_{1,1} * 100$ & 0.0123 & 0.0004 & 0.0110 \\
\hline$\delta_{1,2} * 100$ & -0.0112 & -0.0239 & -0.0035 \\
\hline$\tilde{\sigma}_{\epsilon}^{2}(1) * 12 * 10^{5}$ & 0.0129 & 0.0026 & 0.0162 \\
\hline$\tilde{\sigma}_{\epsilon}^{2}(2) * 12 * 10^{5}$ & 0.0090 & 0.0038 & 0.0504 \\
\hline$\tilde{\sigma}_{\epsilon}^{2}(3) * 12 * 10^{5}$ & 0.0149 & 0.0091 & 0.1011 \\
\hline
\end{tabular}

Note: the Table entries show the estimates for the key parameters of the model. Confidence bounds are constructed by MCMC approach as advocated by Chernozhukov and Hong (2003). 
Table 3: Survey and model inflation expectations (basis points)

\begin{tabular}{ccc}
\hline \hline Year-on-year rate & Model including surveys & Model without surveys \\
\hline in one year & 19 & 26 \\
in two years & 10 & 21 \\
in five years & 6 & 9 \\
\hline
\end{tabular}

Note: The Table reports the differences between the survey inflation expectations at three different horizons and the corresponding model estimates of inflation expectations from our term structure model. Our survey data are form the ECB's Survey of Professional Forecasters, and are compared with two versions of the term structure model, including and not including survey data in the estimation. When survey inflation expectations are included in the estimation we allow for fitting errors in the measurement equation.

Table 4: Volatility of survey and model inflation expectations

\begin{tabular}{cccc}
\hline \hline Horizon & Survey data & Model without surveys & Model including surveys \\
\hline in one year & 20 & 25 & 18 \\
in two years & 11 & 17 & 8 \\
in five years & 5 & 8 & 3 \\
\hline
\end{tabular}

Note: the table entries are the standard deviations of survey inflation expectations and the corresponding estimates from our term structure model for each horizon, in basis points. Our survey data are form the ECB's Survey of Professional Forecasters. Results from two versions of the term structure model, including and not including survey data in the estimation, are reported. The higher volatility of the model inflation expectations without survey data translates into a too low a volatility of inflation risk premia estimates.

Table 5: The fitting of nominal bond yields in different model specifications

\begin{tabular}{ccc}
\hline \hline Horizon & Model without surveys & Model including surveys \\
\hline One year ahead & 12 & 13 \\
Two year ahead & 6 & 7 \\
Five year ahead & 10 & 7 \\
\hline
\end{tabular}

Note: the Table entries report the root mean-square fitting errors for the nominal yields in models including and not including survey inflation expectations. Using survey data does not increase fitting errors significantly. 
Table 6: Decomposing inflation compensation (BEIR)

\begin{tabular}{cccc}
\hline \hline & \multicolumn{3}{c}{ Panel A: Average values 1999-2006 } \\
\hline \hline One-year forward & Inflation compensation & Expected inflation & Inflation risk premia \\
\hline in one year & 2.00 & 1.94 & 0.07 \\
in two years & 1.99 & 1.88 & 0.11 \\
in five years & 2.15 & 1.90 & 0.25 \\
& & & \\
& Panel B: In-sample variance decomposition of inflation compensation \\
\hline \hline & & Expected inflation & Inflation risk premia \\
\hline in one year & & 0.62 & 0.38 \\
in two years & 0.51 & 0.49 \\
in five years & 0.12 & 0.88 \\
\hline
\end{tabular}

Note: Figures are averages of the monthly estimates of inflation compensation (BEIRs), expected inflation and inflation risk premia from our term strucrue model over the sample 1999M1-2006M12.

The variance decomposition of inflation compensation is calculated according to $\frac{\operatorname{cov}\left(B E I R_{t}^{n}, E_{t}\left(\pi_{t}^{n}\right)\right)}{\operatorname{Var}\left(B E I R_{t}^{n}\right)}+\frac{\operatorname{cov}\left(B E I R_{t}^{n}, \phi_{t}^{n}\right)}{\operatorname{Var}\left(B E I R_{t}^{n}\right)}=1$. 
Table 7: The comovement of inflation, expected inflation and inflation risks

\begin{tabular}{|c|c|c|c|c|c|}
\hline & \multicolumn{5}{|c|}{ Panel A: Short-term expectations (one year ahead) } \\
\hline & \multirow{2}{*}{$\begin{array}{l}\text { Level } \\
\text { Mean }\end{array}$} & \multicolumn{2}{|c|}{ Uncertainty } & \multicolumn{2}{|c|}{ Asymmetry } \\
\hline & & Variance & Ave. Unc. & Skewness & Mean-mode \\
\hline Mean & $(0.20)$ & & & & \\
\hline Agg. Variance & -0.3 & $(0.03)$ & & & \\
\hline Ave. Uncertainty & 0.2 & 0.3 & $(0.03)$ & & \\
\hline Skewness & 0.1 & 0.1 & 0.1 & $(0.19)$ & \\
\hline Mean-mode & 0.1 & 0.1 & 0.3 & 1.0 & $(0.10)$ \\
\hline Headline inflation & 0.8 & -0.1 & 0.4 & 0.0 & 0.0 \\
\hline \multirow[t]{4}{*}{ Core inflation } & 0.2 & 0.2 & 0.7 & 0.2 & 0.2 \\
\hline & \multicolumn{5}{|c|}{ Panel B: Long-term expectations (five years ahead) } \\
\hline & Level & \multicolumn{2}{|c|}{ Uncertainty } & \multicolumn{2}{|c|}{ Asymmetry } \\
\hline & Mean & Variance & Ave. Unc. & Skewness & Mean-mode \\
\hline Mean & $(0.05)$ & & & & \\
\hline Agg. Variance & -0.2 & $(0.05)$ & & & \\
\hline Ave. Uncertainty & 0.0 & 0.6 & $(0.05)$ & & \\
\hline Skewness & 0.2 & -0.0 & -0.4 & $(0.13)$ & \\
\hline Mean-mode & 0.2 & 0.0 & -0.4 & 1.0 & $(0.10)$ \\
\hline Headline inflation & 0.3 & -0.1 & 0.1 & 0.2 & 0.2 \\
\hline Core inflation & 0.0 & 0.2 & 0.5 & -0.3 & -0.3 \\
\hline
\end{tabular}

Note: figures within brackets are standard deviations; other entries report correlations. Our survey data are from the ECB's Survey of Professional Forecasters (SPF).Variance refers to the variance of the combined (or aggregate) SPF density forecast constructed by averaging the individual density forecasts; Ave. Uncertainty refers to the average of the variances of the individual forecasts. Risk measures estimated following Garcia and Manzanares (2007). Core inflation refers to the HICP index excluding energy and unprocessed food prices, as published by Eurostat. 
Table 8: Inflation risk premia and inflation risks

\begin{tabular}{|c|c|c|c|c|c|c|}
\hline & \multicolumn{6}{|c|}{ Inflation uncertainty } \\
\hline Horizon & \multicolumn{2}{|c|}{ One year ahead } & \multicolumn{2}{|c|}{ Two years ahead } & \multicolumn{2}{|c|}{ Five years ahead } \\
\hline One-year premium & Variance & Ave. Unc. & Variance & Ave. Unc. & Variance & Ave. Unc. \\
\hline in one year & -0.2 & 0.3 & -0.1 & 0.4 & -0.2 & 0.1 \\
\hline in two years & -0.4 & -0.7 & -0.1 & -0.6 & -0.5 & -0.8 \\
\hline \multirow[t]{2}{*}{ in five years } & -0.2 & -0.3 & 0.2 & -0.2 & -0.3 & -0.4 \\
\hline & \multicolumn{6}{|c|}{ Asymmetry in inflation risks } \\
\hline One-year premium & \multicolumn{2}{|c|}{ One year ahead } & \multicolumn{2}{|c|}{ Two years ahead } & \multicolumn{2}{|c|}{ Five years ahead } \\
\hline in one year & \multicolumn{2}{|c|}{0.1} & \multicolumn{2}{|c|}{0.2} & \multicolumn{2}{|c|}{0.3} \\
\hline in two years & \multicolumn{2}{|c|}{0.3} & \multicolumn{2}{|c|}{0.3} & \multicolumn{2}{|c|}{0.4} \\
\hline in five years & \multicolumn{2}{|c|}{0.3} & \multicolumn{2}{|c|}{0.3} & \multicolumn{2}{|c|}{0.4} \\
\hline
\end{tabular}

Note: our survey data are from the ECB's Survey of Professional Forecasters (SPF). Variance refers to the variance of the combined (or aggregate) SPF density forecast constructed by averaging the individual density forecasts; Ave. Uncertainty refers to the average of the variances of the individual density forecasts. We measure uncertainty by the variance rather than the standard deviation because, by construction, the link between the variance of the combined density forecast and the average of individual variances that does not hold for the standard deviations. Specifically Agg. variance $=$ Average Uncertainty + Disagreement, with average uncertainty being the main component of the variance of the combined probability forecasts. See Garcia and Manzanares (2007) and references therein for details. Inflation risk measures are estimated following Garcia and Manzanares (2007). 
Table 9: Assessing the information content of asymmetries in inflation risks

\begin{tabular}{|c|c|c|c|c|c|c|c|c|c|}
\hline & \multicolumn{9}{|c|}{ Dependent variable is one-year forward inflation risk premium ending in five years } \\
\hline Regressor & 1 & 2 & 3 & 4 & 5 & 6 & 7 & 8 & 9 \\
\hline Constant & $\begin{array}{c}0.21 \\
(0.025)\end{array}$ & $\begin{array}{c}0.07 \\
(0.063)\end{array}$ & $\begin{array}{c}0.27 \\
(0.025)\end{array}$ & $\begin{array}{c}0.22 \\
(0.021)\end{array}$ & $\begin{array}{c}0.33 \\
(0.041)\end{array}$ & $\begin{array}{c}0.32 \\
(0.083)\end{array}$ & $\begin{array}{l}0.31 \\
(0.14)\end{array}$ & $\begin{array}{c}0.21 \\
(0.025)\end{array}$ & $\begin{array}{c}0.30 \\
(0.145)\end{array}$ \\
\hline Inflation skewness (in five years) & $\begin{array}{c}\mathbf{0 . 3 4 * *} \\
(0.097)\end{array}$ & $\begin{array}{c}\mathbf{0 . 3 6 * *} \\
(0.073)\end{array}$ & $\begin{array}{c}\mathbf{0 . 3 8} * * \\
(0.097)\end{array}$ & $\begin{array}{c}-0.00 \\
(0.11)\end{array}$ & $\begin{array}{l}\text { 0.13* } \\
(0.056)\end{array}$ & $\begin{array}{c}\mathbf{0 . 2 9 * *} \\
(0.060)\end{array}$ & $\begin{array}{l}\text { 0.18* } \\
(0.068)\end{array}$ & & \\
\hline Mean-mode (in five years) & & & & & & & & $\begin{array}{c}\mathbf{0 . 4 3 * *} \\
(0.139) \\
\end{array}$ & $\begin{array}{l}\text { 0.21* } \\
(0.094)\end{array}$ \\
\hline Headline inflation & & $\begin{array}{l}-0.07 \\
(0.073)\end{array}$ & & & & & $\begin{array}{c}-0.08^{*} \\
(0.028)\end{array}$ & & $\begin{array}{c}-\mathbf{0 . 0 7 *} \\
(0.031)\end{array}$ \\
\hline Core inflation & & $\begin{array}{l}0.15^{* *} \\
(0.031)\end{array}$ & & & & & $\begin{array}{l}0.11^{* *} \\
(0.022)\end{array}$ & & $\begin{array}{l}0.11 * * \\
(0.024)\end{array}$ \\
\hline Unemployment rate & & & $\begin{array}{c}0.04 \\
(0.042)\end{array}$ & & & & $\begin{array}{l}-0.02 \\
(0.065)\end{array}$ & & $\begin{array}{l}-0.02 \\
(0.063)\end{array}$ \\
\hline Output gap & & & & $\begin{array}{l}8.28 * \\
(0.073)\end{array}$ & & & $\begin{array}{l}-0.85 \\
(4.201)\end{array}$ & & $\begin{array}{l}-0.50 \\
(4.191)\end{array}$ \\
\hline Consumer confidence & & & & & $\begin{array}{l}0.01 * \\
(0.003)\end{array}$ & & $\begin{array}{l}0.01 * \\
(0.004)\end{array}$ & & $\begin{array}{l}0.01 * \\
(0.004)\end{array}$ \\
\hline Yield curve slope & & & & & & $\begin{array}{l}0.08^{*} \\
(0.031)\end{array}$ & $\begin{array}{l}0.05^{*} \\
(0.022)\end{array}$ & & $\begin{array}{l}0.05^{*} \\
(0.023)\end{array}$ \\
\hline Bond market implied volatility & & & & & & $\begin{array}{c}-0.07 * * \\
(0.019)\end{array}$ & $\begin{array}{l}-0.04 \\
(0.021)\end{array}$ & & $\begin{array}{l}-0.04 \\
(0.022)\end{array}$ \\
\hline VIX & & & & & & $\begin{array}{l}0.01 * * \\
(0.002)\end{array}$ & $\begin{array}{l}0.01^{*} \\
(0.019)\end{array}$ & & $\begin{array}{l}0.01^{*} \\
(0.019)\end{array}$ \\
\hline$R$-bar-square & 0.20 & 0.21 & 0.19 & 0.41 & 0.36 & 0.56 & 0.84 & 0.18 & 0.84 \\
\hline RSS & 0.15 & 0.07 & 0.15 & 0.11 & 0.11 & 0.07 & 0.02 & 0.15 & 0.02 \\
\hline Regression F-Statistic (p-value) & 0.017 & 0.018 & 0.042 & 0.003 & 0.002 & 0.000 & 0.001 & 0.021 & 0.000 \\
\hline
\end{tabular}

Note: each column reports a regression of the long-term inflation risk premium on our two measures of perceived asymmetries in inflation risks (inflation skewness measured by the standard normalised third moment and the distance between the mean and the mode of the density forecast) and different combinations of macroeconomic and financial factors. Perceived inflation risks are estimated from the inflation density forecasts of the ECB's SPF five years ahead following Garcia and Manzanares (2007). Sample is 2001Q1 to 2006Q4. Inflation is measured as the year-onyear rate of growth of the HICP computed by Eurostat; core refers to HICP excluding energy and unprocessed food prices. The output gap is estimated from HP filtered quarterly real GDP data between 1995-2006. Consumer confidence is from the EC surveys. Yield curve slope is measured as the 2- and 10-year yield spread. ** indicates significance at $1 \%$ and * at $5 \%$. Numbers in brackets are Newey-West robust standard errors. 


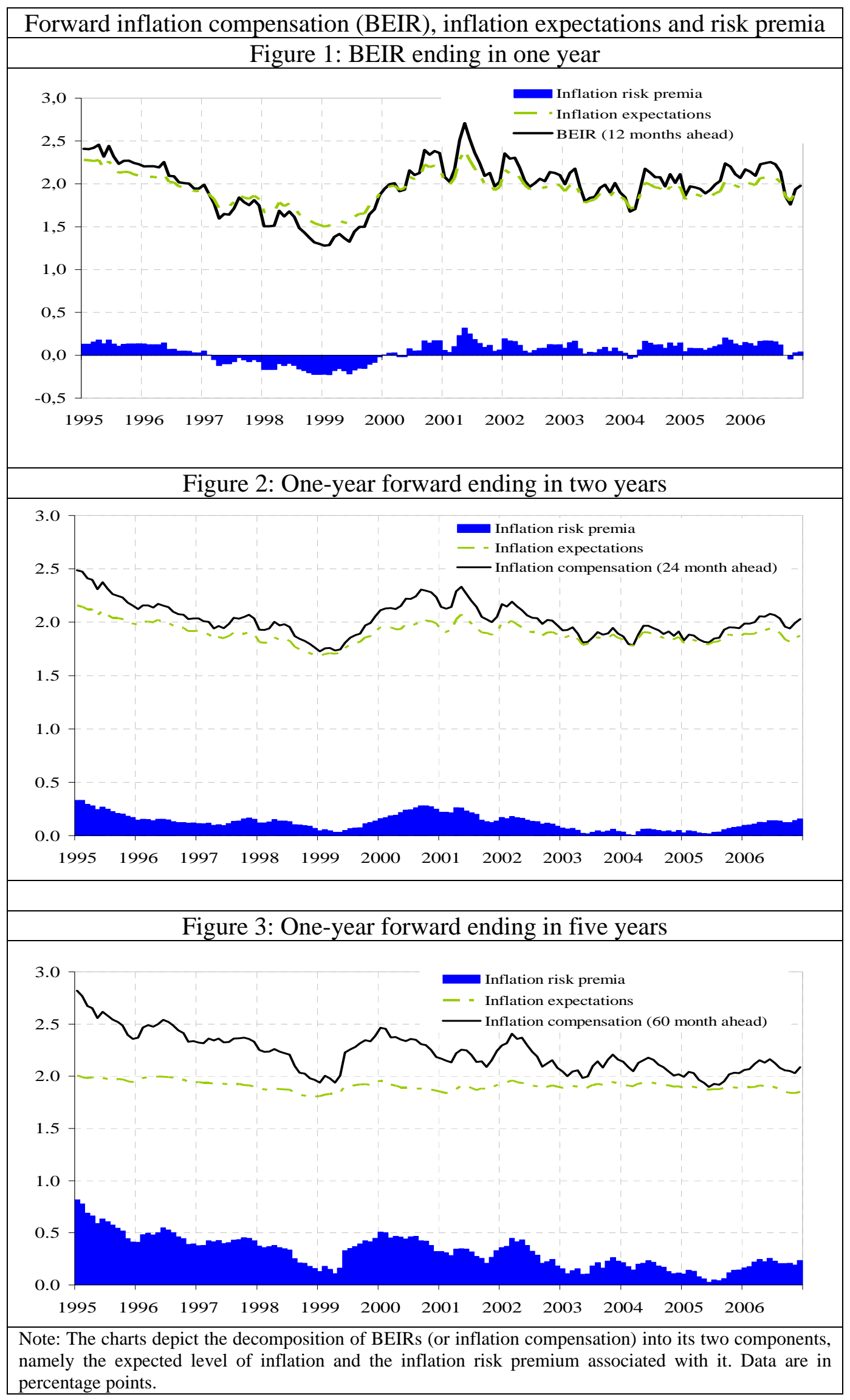




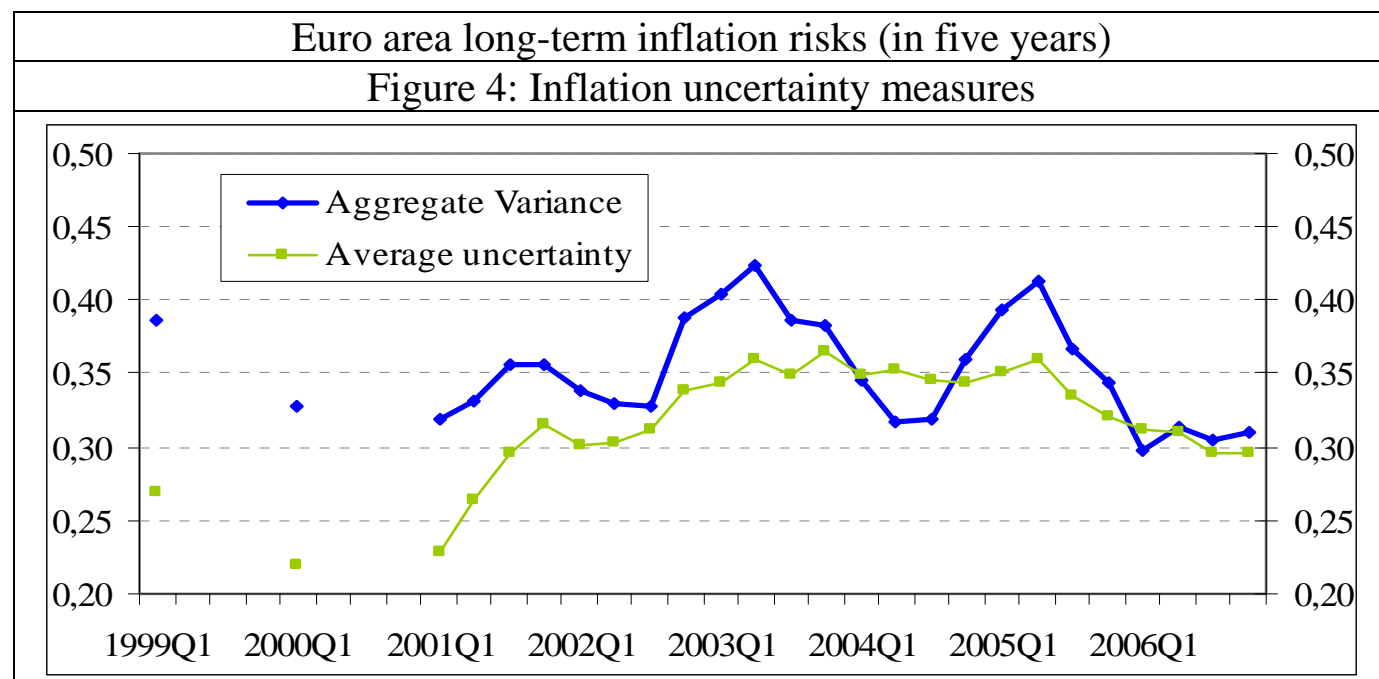

Figure 5: Asymmetries in long-term inflation risks

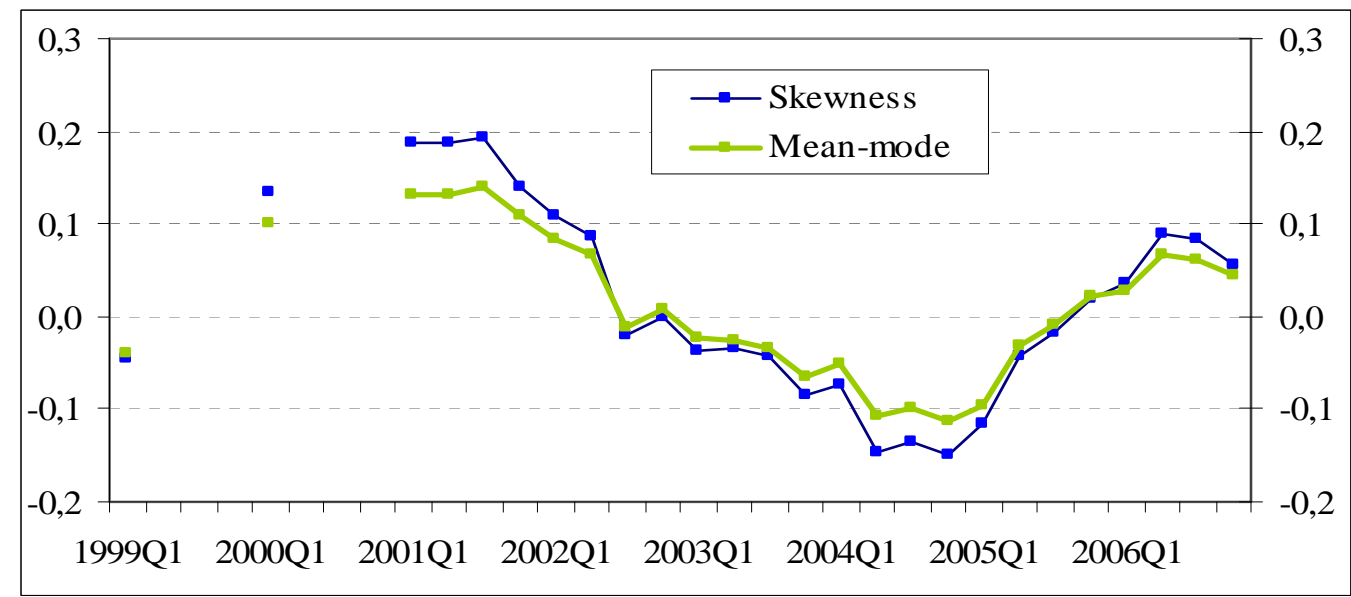

Note: Aggregate Variance in Figure 4 refers to the variance of the combined (or aggregate) SPF density forecast constructed by averaging the individual density forecasts (histograms); Average Uncertainty is the average of the variances of the individual density forecasts. By construction, Aggregate Variance is the sum of Average Uncertainty and the Variance of the means of the individual probability forecasts (disagreement). For that reason we report uncertainty measures based on the second moments of both the individual and the combined probability forecast. Skewness and Mean-mode in Figure 5 measure the asymmetry in the combined (or aggregate) SPF density forecast, three-quarter centred moving averages. Garcia and Manzanares (2007) introduces the methodology for the estimation of the inflation risk measures employed in this paper and discusses them in detail. 


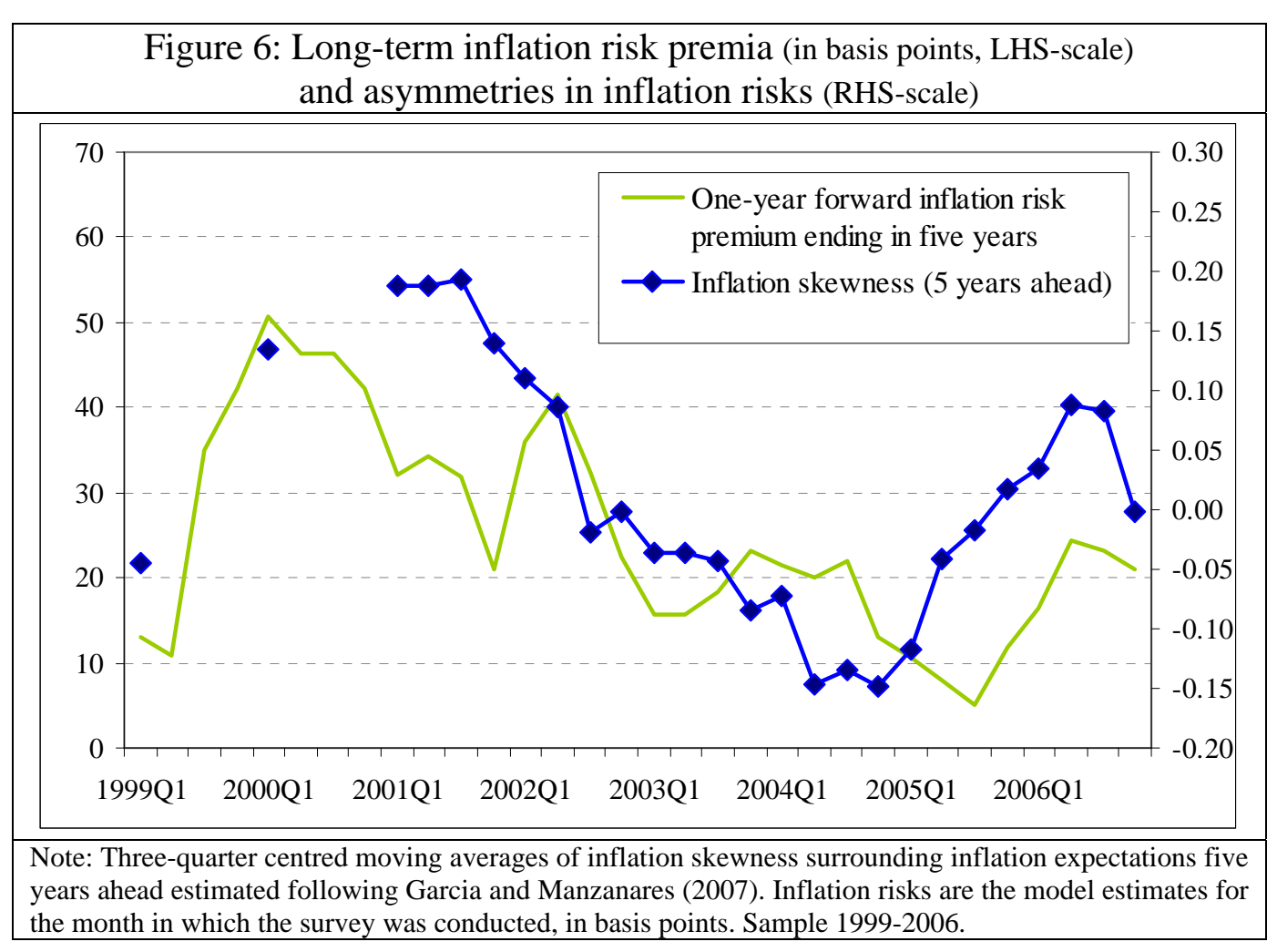


